\title{
¿Spectrally Resolved Fluxes from IASI Data: Retrieval Algorithm for Clear-Sky Measurements
}

\author{
Simon Whitburn, ${ }^{\mathrm{a}}$ Lieven Clarisse, ${ }^{\mathrm{a}}$ Sophie BAuduin, ${ }^{\mathrm{a}}$ MAyA GeOrge, ${ }^{\mathrm{b}}$ DANiel Hurtmans, ${ }^{\mathrm{a}}$ \\ SARAh SAFIEddine, ${ }^{\mathrm{b}}$ Pierre FranÇOIS COHEUR, ${ }^{\mathrm{a}}$ AND CATHy Clerbaux ${ }^{\mathrm{b}}$ \\ ${ }^{a}$ Atmospheric Spectroscopy, Service de Chimie Quantique et Photophysique, Université libre de Bruxelles, Brussels, Belgium \\ ${ }^{b}$ LATMOS/IPSL, Sorbonne Université, UVSQ, CNRS, Paris, France
}

(Manuscript received 17 July 2019, in final form 21 March 2020)

\begin{abstract}
Space-based measurements of the outgoing longwave radiation (OLR) are essential for the study of Earth's climate system. While the CERES instrument provides accurate measurements of this quantity, its measurements are not spectrally resolved. Here we present a high-resolution OLR product (sampled at $0.25 \mathrm{~cm}^{-1}$ ), derived from measurements of the IASI satellite sounder. The applied methodology relies on precalculated angular distribution models (ADMs). These are usually calculated for tens to hundreds of different scene types (characterized by surface and atmosphere parameters). To guarantee accurate results in the range $645-2300 \mathrm{~cm}^{-1}$ covered by IASI, we constructed ADMs for over 140000 scenes. These were selected from one year of CAMS reanalysis data. A dissimilarity-based selection algorithm was applied to choose scenes as different from each other as possible, thereby maximizing the performance on real data, while keeping the number of scenes manageable. A comparison of the IASI OLR integrated over the 645$2300 \mathrm{~cm}^{-1}$ range was performed with the longwave broadband OLR products from CERES and the AIRS instrument. The latter are systematically higher due to the contribution of the far infrared to the total IR spectral range, but as expected exhibit generally high spatial correlations with the IASI OLR, except for some areas in the tropical region. We also compared the IASI OLR against the spectrally resolved OLR derived from AIRS. A good agreement was found above $1200 \mathrm{~cm}^{-1}$ while AIRS OLR appeared to be systematically higher in the atmospheric window region, likely related to differences in overpass time or to the use of a different cloud detection algorithm.
\end{abstract}

\section{Introduction}

The top-of-the-atmosphere (TOA) thermal flux, also referred to as Earth's outgoing longwave radiation (OLR) $\left(\mathrm{W} \mathrm{m}^{-2}\right)$, represents the total radiation emitted by the Earth-atmosphere system into space. As part of Earth's radiation budget, it reflects how the Earth-atmosphere system balances the incoming solar radiation at the top of the atmosphere and corresponds to about $2 / 3$ of the total outgoing radiation, with the remaining $1 / 3$ being reflected solar radiation (Trenberth et al. 2009). An accurate determination of the OLR is essential to improve our ability to model

Denotes content that is immediately available upon publication as open access.

Corresponding author: Simon Whitburn, simon.whitburn@ulb. ac.be
Earth's climate system and to monitor climate feedbacks and processes (Brindley et al. 2015). Since the OLR is affected by clouds, aerosols, water vapor $\left(\mathrm{H}_{2} \mathrm{O}\right)$, and other greenhouse gases, this requires a good understanding of their impact on Earth's climate. Despite the numerous studies achieved in the last decades (e.g., Soden et al. 2005; Anderson et al. 2010; Y. Huang et al. 2010; Feldman et al. 2011), uncertainties up to a few percent remain, especially for net TOA integrated fluxes (e.g., Loeb et al. 2009; Trenberth et al. 2009; Stephens et al. 2012; Wild et al. 2014).

In principle, infrared sounding satellites are ideal for measuring the spectrally resolved OLR $F_{\nu}(x, y, t)\left[\mathrm{W} \mathrm{m}^{-2}\right.$ $\left.\left(\mathrm{cm}^{-1}\right)^{-1}\right]$ at different locations $(x, y)$ and times $(t)$ on Earth as they observe the Earth-atmosphere system from above. Satellites however measure the radiance intensities $L_{\nu}(x, y, t, \theta, \phi)\left[\mathrm{W} \mathrm{m}^{-2} \mathrm{sr}^{-1}\left(\mathrm{~cm}^{-1}\right)^{-1}\right]$ at a specific solid angle $d \Omega=\sin (\theta) d \theta d \phi$ that need to be integrated 
over all the zenith $(\theta)$ and azimuth directions $(\phi)$ for the conversion to the OLR:

$$
F_{\nu}(x, y, t)=\int_{\theta=0}^{\pi / 2} \int_{\phi=0}^{2 \pi} L_{\nu}(x, y, t, \theta, \phi) \cos (\theta) \sin (\theta) d \theta d \phi .
$$

For an isotropic radiance field, the conversion to the OLR simplifies to $F_{\nu}(x, y, t)=\pi L_{\nu}(x, y, t, \theta, \phi)$, but this is an idealized case that is never exactly met in reality. As satellite instruments generally acquire the radiance at a limited number of (or single) viewing angle directions for a given scene $(x, y, t)$ the integral cannot be evaluated exactly. This problem is usually overcome by using empirical angular distribution models (ADMs), which allow characterizing the angular dependence of Earth's radiation field for different scene types (denoted $s$ ) with distinct surface and atmospheric anisotropic characteristics. Each of these ADMs consists of a set of anisotropic factors $\left[R_{s, \nu}(\theta, \phi)\right]$ defined as the ratio of the equivalent Lambertian flux to the actual flux (Smith et al. 1986; Suttles et al. 1988) that directly link the directional radiance observations to the OLR [for simplicity, the dependencies on $x, y$, and $t$ for $L_{\nu}(\theta, \phi)$ and $F_{\nu}$ are omitted hereafter]:

$$
F_{\nu}=\frac{\pi L_{\nu}(\theta, \phi)}{R_{s, \nu}(\theta, \phi)}
$$

The ADMs can be derived directly from the radiance measurements relying on the so-called sorting into angular bins method (Suttles et al. 1989) or calculated from synthetic spectra constructed for different angles of view using radiative transfer models (e.g., Huang et al. 2008).

The very first OLR measurements were collected by the Explorer VII satellite launched in 1959 (Suomi 1960), which operated for a period of 7 months. It was not until the mid-1970s that global coverage and multiyear time scale OLR retrieval and monitoring started with the launch of the broadband Earth Radiation Budget (ERB) instruments on board the Nimbus-6 and Nimbus-7 satellites in 1975 and 1978, respectively (Jacobowitz et al. 1979, 1984; Taylor and Stowe 1984). Since then, OLR has been monitored globally by a number of instruments, and currently a continuous time series over more than 40 years is available. An overview of the principal satellite missions dedicated to the measurement of OLR is given in Table 1. In particular, these include the Earth Radiation Budget Experiment (ERBE) instruments on the ERBS, NOAA-9 and -10 satellites (between 1984 and 1992) (Barkstrom and Smith 1986), followed by the Scanner for Radiation Budget (ScaRaB) on board the Meteor 3/7, Resurs O1-4, and Megha-Tropiques satellites and the series of Clouds and the Earth's Radiant Energy System (CERES), which have flown on EOS Terra and Aqua since 2000 and 2002 (Wielicki et al. 1996), respectively, on the Suomi NPOESS Preparatory Project (S-NPP) since 2011 (Thomas et al. 2012) and most recently on NOAA-20 since 2017 . For each of these instruments, a set of empirical ADMs has been derived for different scene types. For ERB, scene types were limited to 8 (land, water, snow, ice; low, middle, and high water and high ice clouds) (Taylor and Stowe 1984) while the set was extended to 12 for the ERBE and the ScaRaB instruments, based on latitude zones, seasons, surface types, and cloud fractions (Smith et al. 1986; Kandel et al. 1998). For CERES, the radiance-to-flux conversion was improved by increasing the number of ADMs to several hundreds. This was done by taking advantage of the spectral information from coincident measurements of the high spatial resolution spectral imagers MODIS and SSM/I, allowing the retrieval of parameters with a strong influence on the anisotropy (e.g., the cloud infrared emissivity) (Loeb et al. 2003, 2005). In addition to these instruments, another major contribution to the OLR data records that is worth mentioning comes from the High Resolution Infrared Radiation Sounders (HIRS), which flies on board the NOAA TIROS- $N$ and MetOp suite of satellites and provides continuous measurements of Earth's radiance since 1979 (Ellingson et al. 1989; Lee and Ellingson 2013).

Taking advantage of multidecadal records of these dedicated broadband instruments, derived OLR has been widely used in climate studies as a proxy for convection and rainfall activity (e.g., Kidson et al. 2002; Jones et al. 2004; Barlow et al. 2005; Kiladis et al. 2005; Chiodi and Harrison 2010; Loeb et al. 2012; Susskind et al. 2012), in the study of Earth's radiation budget (e.g., Clement and Soden 2005; Fasullo and Trenberth 2008), in atmospheric model validation (Allan and Ringer 2003), and for the study of climate feedback and processes (e.g., Ohring and Gruber 1983; Lau and Chan 1983a,b; Chu and Wang 1997; Chung et al. 2010; Trenberth et al. 2010). However, such broadband instruments only provide an integrated OLR estimate over a broad spectral range (typically in the range $50-2000 \mathrm{~cm}^{-1}$ ). They are therefore not well suited for tracking separately the impact of the different parameters affecting the OLR (including greenhouse gases), making it difficult to track down deficiencies in climate models (Huang et al. 2006, 2008). A better constraint of the OLR can, in principle, be obtained from spectrally resolved OLR (i.e., the integrand of broadband OLR) derived from infrared hyperspectral sounders. Currently, several hyperspectral sounders in space acquire radiances in the thermal infrared spectral range. Until now, their measurements have however not been much exploited in the study of OLR. An important work has been accomplished by Huang et al. and Chen 
et al. (see references just below) in a series of studies focusing on the development of retrieval algorithms for the conversion of the directional radiances measured by the Atmospheric Infrared Sounder [AIRS (Aqua); Aumann et al. 2003] to spectral fluxes at a spectral resolution of $10 \mathrm{~cm}^{-1}$ for both clear and cloudy skies (Huang et al. 2008; X. Huang et al. 2010; Chen et al. 2013; Huang et al. 2014; Chen and Huang 2016) (see Table 1). The strategy for the conversion of directional radiance to flux was the same as for broadband instruments (i.e., based on the determination of empirical ADMs). For clear-sky conditions, scene types for the construction and use of ADMs were characterized by the surface temperature $\left(T_{s}\right)$, the thermal contrast $\left(\Delta T_{a}\right)$, and the precipitable water (pw). These were taken from the CERES Single Satellite Footprint (SSF) dataset and directly applicable to collocated AIRS observation since both instruments are on the same platform. For the wavenumbers not covered by the instrument, spectral fluxes were derived from a multiregression scheme based on the principal component analysis. By comparing the AIRS-derived OLR with simulations of the AM2 general circulation model developed at the Geophysical Fluid Dynamics Laboratory (GFDL), Huang et al. (2008) highlighted a series of biases in the model temperature, $\mathrm{H}_{2} \mathrm{O}$, and carbon dioxide $\left(\mathrm{CO}_{2}\right)$ absorption bands, as well as in specific cloud regimes and seasonal troposphere relative humidity. It appeared that these biases could compensate each other so that these do not show up in comparisons of broadband fluxes.

Several other studies have exploited AIRS radiance measurements but for the derivation of broadband OLR In particular, Susskind et al. (2003) have computed OLR and OLR $_{\text {CLR }}$ (clear sky) using a radiative transfer algorithm by taking as input a series of atmospheric parameters generated from the AIRS Science Team retrieval algorithm. Two other studies, Sun et al. (2010) and Zhang et al. (2017), have developed a broadband OLR product for AIRS and its successor, the Cross-Track Infrared Sounder [CrIS (S-NPP); Han et al. 2013], respectively, based on a statistical comparison of the measured radiance with the CERES OLR taken as reference.

The Infrared Atmospheric Sounding Interferometer (IASI; Clerbaux et al. 2009; Hilton et al. 2012) is a hyperspectral infrared sounder just like AIRS and CrIS, but covers a larger part of the thermal infrared region $\left(645-2760 \mathrm{~cm}^{-1}\right)$, without any gaps, making it more suitable to derive spectral OLR (Fig. 1). Its spectra are postapodized at a uniform sampling of $0.25 \mathrm{~cm}^{-1}$ and a spectral resolution of $0.5 \mathrm{~cm}^{-1}$. IASI covers Earth twice daily, crossing the equator at $\sim 9: 30$ a.m. and p.m. local time (0930 and $2100 \mathrm{LT}$ ). Its track corresponds to $2 \times 15$ instantaneous field of view (FOV), each of them being composed of $2 \times 2$ elliptical pixels. So far, IASI has gathered 12 years of continuous measurements (with the perspective of another 6 years at least with the recent launch of $\mathrm{MetOp}-\mathrm{C}$ in November 2018). To our knowledge, no spectral OLR product has been developed for IASI. Turner et al. (2015) have described a method to derive high-resolution TOA spectral radiances at nadir over the entire longwave spectrum of Earth based on correlation between different channels measured by IASI and unobserved radiances. These were used in Turner (2015) in combination with empirical ADMs to derive broadband OLR, but no attempt was made to calculate spectrally resolved fluxes. Two other studies, Brindley et al. (2015) and Bantges et al. (2016), have studied interannual variability of the raw IASI spectra to identify changes in regions affected by feedback processes.

Here, we propose a dedicated retrieval algorithm for deriving spectral OLR from the IASI measurements at a spectral sampling of $0.25 \mathrm{~cm}^{-1}$. The focus is on clear-sky scenes only. An upper bound of $2300 \mathrm{~cm}^{-1}$ was chosen to exclude spectral regions where the solar reflectance affects the spectrum. Like most other OLR retrieval algorithms, the method relies on the use of precalculated ADMs. However, to achieve a good accuracy at the single-channel level, the ADMs were constructed for a much larger number of scenes than ever before (over 140000 in total), accounting for variations in surface and atmospheric temperature and all six principal infrared absorbers $\left[\mathrm{H}_{2} \mathrm{O}\right.$, methane $\left(\mathrm{CH}_{4}\right)$, ozone $\left(\mathrm{O}_{3}\right)$, carbon monoxide $(\mathrm{CO})$, nitrous oxide $\left(\mathrm{N}_{2} \mathrm{O}\right)$, and $\left.\mathrm{CO}_{2}\right]$. These scenes were selected from an even larger set of over three million scenes of global data provided by Copernicus Atmosphere Monitoring Service (CAMS) using a dissimilarity-based subset selection algorithm (Snarey et al. 1997). Section 2 describes the selection procedure of representative scene types and the construction of associated spectrally resolved ADMs. The retrieval of OLR itself is presented in section 3. Section 4 and 5 show a first comparison with CERES and AIRS integrated OLR and with the AIRS spectrally resolved OLR product from Huang et al. and Chen et al. (Huang et al. 2008; X. Huang et al. 2010; Chen et al. 2013; Huang et al. 2014; Chen and Huang 2016). Conclusions and perspectives are given in section 6 . The main steps of the method are summarized in Fig. 2.

\section{Construction of spectrally resolved ADMs}

This section describes how the ADMs were built (Fig. 2, upper box). Since we are interested in spectrally resolved fluxes, the anisotropic factors $R_{s, \nu}(\theta)$ are not only a function of the scene type $(s)$ and zenith angle $(\theta)$, as is the case for broadband instruments, but also of the frequency $\nu$. Because thermal radiance is independent 
TABLE 1. Key satellite missions for OLR observations and main related retrieval algorithms.

\begin{tabular}{|c|c|c|c|c|}
\hline Instrument & Platform & Lifespan & Studies & Short algorithm description \\
\hline \multicolumn{5}{|c|}{ Broadband $O L R$} \\
\hline $\begin{array}{l}\text { WFOV } \\
\text { radiometer }\end{array}$ & Explorer VII & $1959-60$ & Suomi (1960) & First usable measurements of OLR collected. \\
\hline HIRS & $\begin{array}{l}\text { NOAA TIROS-N, } \\
\quad \text { MetOp }\end{array}$ & 1976-present & $\begin{array}{l}\text { Ellingson et al. (1989), } \\
\text { Lee and } \\
\text { Ellingson (2013) }\end{array}$ & $\begin{array}{l}\text { OLR estimated from a multispectral regression } \\
\text { model from the radiances of } 4 \text { of the HIRS } \\
\text { channels. }\end{array}$ \\
\hline ERB & Nimbus-6, -7 & $1975-94$ & $\begin{array}{l}\text { Jacobowitz et al. (1979), } \\
\text { Taylor and } \\
\text { Stowe (1984) }\end{array}$ & $\begin{array}{l}\text { ADMs built using the sorting-into-angular bins } \\
\text { (SAB) method for } 8 \text { surface types and dif- } \\
\text { ferent cloud fraction. }\end{array}$ \\
\hline ERBE & ERBS, NOAA-9, -10 & 1984-92 & $\begin{array}{l}\text { Barkstrom (1984), } \\
\text { Smith et al. (1986), } \\
\text { Suttles et al. (1989) }\end{array}$ & $\begin{array}{l}\text { ADMs built using the SAB method for } 12 \text { scene } \\
\text { classifications of different surface type and } \\
\text { cloud fraction. Scene type determined using } \\
\text { the maximum likelihood estimation } \\
\text { technique which compares the measured } \\
\text { radiances to a predefined set of radiances for } \\
\text { different geometries of view and } \\
\text { geographic zones. }\end{array}$ \\
\hline ScaRaB & $\begin{array}{l}\text { Meteor-3/7, } \\
\quad \text { Resurs } 01-4, \\
\text { Megha-Tropiques }\end{array}$ & $\begin{array}{l}\text { 1994-95, } \\
\text { 1998-99, } \\
\text { 2011-today }\end{array}$ & $\begin{array}{l}\text { Kandel et al. (1998), } \\
\text { Duvel et al. (2001), } \\
\text { Sathiyamoorthy } \\
\text { et al. (2013) }\end{array}$ & $\begin{array}{l}\text { Same } 12 \text {-scene classification and ADM tables } \\
\text { as ERBE. }\end{array}$ \\
\hline $\begin{array}{l}\text { GERB } \\
\text { (broadband) }+ \\
\text { SEVIRI } \\
\text { (narrowband) }\end{array}$ & $\begin{array}{l}\text { MeteoSat }-8,-9,-10,-11 \\
\quad(\text { geostationary) }\end{array}$ & 2002-today & $\begin{array}{l}\text { Bertrand et al. (2004), } \\
\quad \text { Clerbaux et al. (2003) }\end{array}$ & $\begin{array}{l}\text { Radiance-to-flux conversion from modeling of } \\
\text { the limb darkening based on the SEVIRI } \\
\text { thermal channels. }\end{array}$ \\
\hline CERES PFM & TRMM & $1997-2000$ & Loeb et al. (2003) & $\begin{array}{l}\text { Same as for the other CERES instruments (see } \\
\text { below) but with less scene types identified } \\
\text { from VIRS data. }\end{array}$ \\
\hline CERES & $\begin{array}{l}\text { Terra (FM1 and FM2), } \\
\text { Aqua (FM3 and FM4), } \\
\text { NPP (FM5), } \\
\text { NOAA-20(FM6) }\end{array}$ & $\begin{array}{l}\text { 1999-today, } \\
\text { 2002-today, } \\
\text { 2011-today, } \\
\text { 2017-today }\end{array}$ & $\begin{array}{l}\text { CERES Science Team, } \\
\text { Loeb et al. (2005), } \\
\text { Su et al. (2015), } \\
\text { Loeb et al. (2018) }\end{array}$ & $\begin{array}{l}\text { Several hundreds of scene type dependent } \\
\text { ADMs built using the SAB bins method from } \\
\text { CERES measurements working in rotating } \\
\text { azimuth plane (RAP) mode. Scene type } \\
\text { described by surface type (6, from IGBP) } \\
\text { stratified into intervals of precipitable water } \\
\text { (pw), surface temperature }\left(T_{s}\right) \text {, thermal } \\
\text { contrast }\left(\Delta T_{a}\right) \text {, cloud fraction and cloud } \\
\text { infrared emissivity. Scene information are } \\
\text { derived from MODIS and SSM/I } \\
\text { measurements as well as from 4D } \\
\text { assimilation data (GMAO GEOS Data } \\
\text { Assimilation System). }\end{array}$ \\
\hline AIRS & Aqua & 2002-today & $\begin{array}{l}\text { AIRS Science Team } \\
\text { (version 6), Susskind } \\
\text { et al. (2003, 2011, } \\
\text { 2012, 2014) }\end{array}$ & $\begin{array}{l}\text { OLR and OLR } \mathrm{CLR}_{\text {(clear sky) computed as the }} \\
\text { sum of the fluxes in } 16 \text { contiguous spectral } \\
\text { bands evaluated from } T_{s}, \text { emissivity } \varepsilon_{s, \nu}, T(p), \\
q(p)\left(\text { water vapor profile), } \mathrm{O}_{3}(p), \mathrm{CO}_{2}(p),\right. \\
\mathrm{CO}(p), \mathrm{CH}_{4}(p), \mathrm{N}_{2} \mathrm{O}(p), \text { and cloud } \\
\text { parameters with the AIRS Science Team } \\
\text { Retrieval Algorithm. }\end{array}$ \\
\hline
\end{tabular}

of the relative azimuth angle on average, azimuthal $(\phi)$ symmetry is assumed here (Suttles et al. 1989; Clerbaux et al. 2003). Equations (1) and (2) become

$$
F_{\nu}=2 \pi \int_{\theta=0}^{\pi / 2} L_{\nu}(\theta) \cos (\theta) \sin (\theta) d \theta
$$

$$
F_{\nu}=\frac{\pi L_{\nu}(\theta)}{R_{s, \nu}(\theta)}
$$

\section{a. Selection of a set of diverse scene types}

To build a comprehensive and relevant set of ADMs for spectral OLR, we need a collection of scene types as 
TABLE 1. (Continued)

\begin{tabular}{|c|c|c|c|c|}
\hline Instrument & Platform & Lifespan & Studies & Short algorithm description \\
\hline \multicolumn{5}{|c|}{ Spectrally resolved $O L R$} \\
\hline AIRS & Aqua & 2002-today & $\begin{array}{l}\text { Huang et al. (2008), } \\
\text { X. Huang et al. } \\
\text { (2010), Chen } \\
\text { et al. (2013), } \\
\text { Huang et al. } \\
\text { (2014), Chen and } \\
\text { Huang (2016) }\end{array}$ & $\begin{array}{l}\text { Construction of scene type dependent ADMs } \\
\text { from synthetic spectra built with the } \\
\text { MODTRAN5 RT model using } T_{s}, \Delta T_{a} \text {, and } \\
\text { pw from ECMWF ERA-40 reanalysis. For } \\
\text { clear and cloud scenes. Scene information } \\
\text { taken from CERES SSF dataset and directly } \\
\text { applicable to AIRS observations. Fluxes at } \\
\text { spectral bands not covered by AIRS esti- } \\
\text { mated by multivariate linear regression } \\
\text { scheme. Spectral resolution of } 10 \mathrm{~cm}^{-1} \text {. }\end{array}$ \\
\hline \multirow[t]{2}{*}{ IASI } & $\begin{array}{l}\text { MetOp-A, } \\
\text { MetOp-B, } \\
M e t O p-C\end{array}$ & $\begin{array}{l}\text { 2006-today, } \\
\text { 2012-today, } \\
\text { 2018-today }\end{array}$ & Turner et al. (2015) & $\begin{array}{l}\text { Construction of high-resolution TOA spectral } \\
\text { radiance over the whole LW spectrum of } \\
\text { Earth based on correlation between different } \\
\text { channels measured by IASI and unobserved } \\
\text { wavenumbers. No OLR derived. }\end{array}$ \\
\hline & & & This work & $\begin{array}{l}\text { Spectrally resolved OLR for clear-sky obser- } \\
\text { vations at a spectral sampling of } 0.25 \mathrm{~cm}^{-1} \text {. } \\
\text { Spectral ADMs built from synthetic spectra } \\
\text { with the Atmosphit line-by-line RT model for } \\
\text { more than } 23000 \times 6 \text { distinct scene types } \\
\text { characterized by } T_{s}, T_{a}, \mathrm{H}_{2} \mathrm{O}, \mathrm{O}_{3}, \mathrm{CO} \text {, and } \\
\mathrm{CH}_{4} \text { from the CAMS reanalysis; in addition } \\
\text { to climatological } \varepsilon_{s, \nu} \text { and } \mathrm{CO}_{2} \text { and } \mathrm{N}_{2} \mathrm{O} \text {. }\end{array}$ \\
\hline
\end{tabular}

diverse as possible and representative of those encountered in the Earth-atmosphere system. The surface and atmospheric parameters that affect the anisotropy of the radiance field are multiple. In total, nine parameters were retained for the scene types description. These are the six main thermal infrared absorbers of the atmosphere $\left(\mathrm{H}_{2} \mathrm{O}, \mathrm{CO}_{2}, \mathrm{O}_{3}, \mathrm{~N}_{2} \mathrm{O}\right.$, $\left.\mathrm{CO}, \mathrm{CH}_{4}\right)$, the surface temperature $\left(T_{s}\right)$ and emissivity $\left(\varepsilon_{s, \nu}\right)$, and the atmospheric temperature $\left(T_{a}\right)$ evaluated at 0 , 5,10 , and $15 \mathrm{~km}$ (Clerbaux et al. 2009; Susskind et al. 2012). The way each of them affects the ADM is further addressed.

For the selection of the collection of scene types, we started from the data from the Copernicus Atmosphere Monitoring Service (CAMS) reanalysis, the latest global reanalysis dataset of atmospheric composition produced by the European Center for Medium-Range Weather

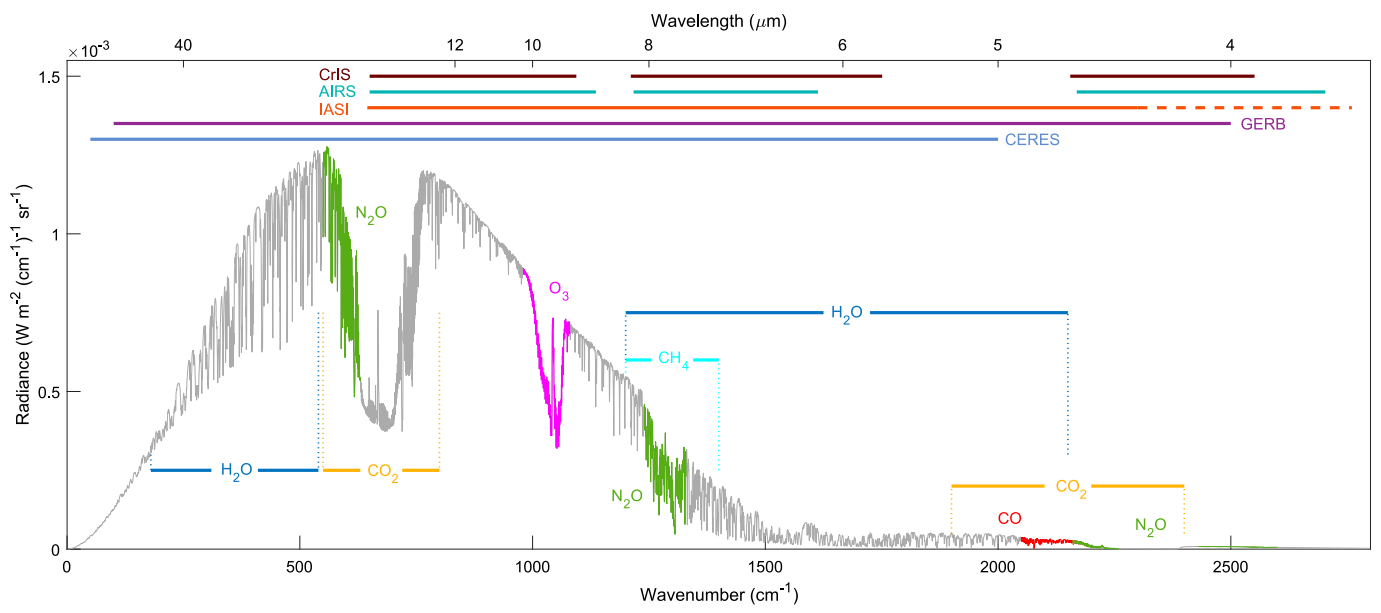

FIG. 1. (top) The spectral range covered by the three hyperspectral sounders IASI (orange), CrIS (brown), and AIRS (cyan) and by the two broadband instruments CERES (blue) and GERB (purple). For IASI, the spectral range extends from 645 to $2760 \mathrm{~cm}^{-1}$ but is limited to $2300 \mathrm{~cm}^{-1}$ in this work for the derivation of the spectral OLR (solid line). (bottom) An example is given of a thermal infrared spectrum with the region of absorption of the six principal absorbers superimposed $\left(\mathrm{H}_{2} \mathrm{O}, \mathrm{CO}_{2}, \mathrm{O}_{3}, \mathrm{~N}_{2} \mathrm{O}, \mathrm{CO}, \mathrm{CH}_{4}\right)$. 


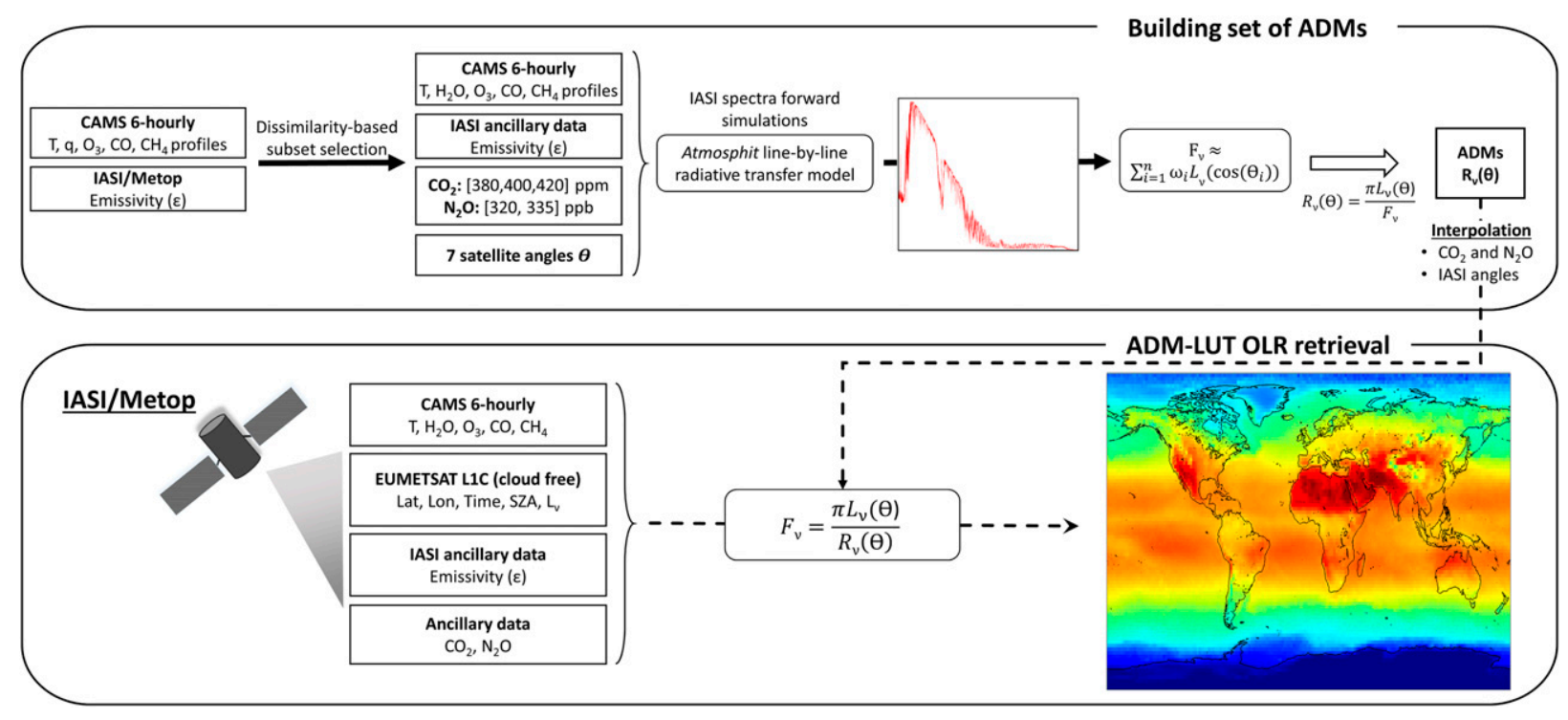

FIG. 2. Conceptual flowchart of the OLR retrieval algorithm.

Forecasts (ECMWF) (Inness et al. 2019). The CAMS reanalysis consists of three-dimensional time-consistent atmospheric composition and surface fields. It is distributed at a $0.25^{\circ} \times 0.25^{\circ}$ spatial resolution and includes all the atmospheric and surface parameters of interest except $\mathrm{CO}_{2}$ and $\mathrm{N}_{2} \mathrm{O}$ (but are intended to be included at some point) and the surface emissivities $\varepsilon_{s}$. Both total columns and profiles (at 24 pressure levels) are provided for the trace gases. The dataset covers currently the period 2003-17 and is planned to be extended in the future. For the surface emissivities over land, we relied on the 2014 monthly mean spectral emissivity database provided by Zhou et al. (2011). Over seas, emissivities were taken from the Nalli et al. (2008) emissivity database. For the scene type descriptions, an average emissivity over the atmospheric window 800-1010; $1065-1200 \mathrm{~cm}^{-1}$ was considered, thereby excluding the $1010-1065 \mathrm{~cm}^{-1}$ range corresponding to the $\nu_{3}$ ozone band. $\mathrm{CO}_{2}$ and $\mathrm{N}_{2} \mathrm{O}$, which are not currently provided in the CAMS dataset, were not included in the selection process. The way in which they were taken into account for the construction of the ADMs is addressed at the end of this section. Three days per month of CAMS data from the year 2016 were used. The dataset was obtained at a 6-h temporal resolution. The selection stage was performed in two steps: 1) from each day, 100000 scenes were randomly selected. Because the mesh surface of the grid decreases as we move toward the poles, a weighting cosine function was applied to equally distribute the number of scenes around the globe. The resulting dataset is composed of 3.6 million scenes and includes $T_{s}, T_{a}$, and the four selected trace gases both in total column and profiles. For each of them, the corresponding surface emissivity was calculated. 2) From this initial collection of scene types, a subset including representatives of all the diversity encountered was isolated. In practice, all scenes that were too similar to each other were removed. Similarity was expressed by setting a threshold $(T)$ for each of the parameters $(p)$ so that two scenes are considered similar when $\left|p_{i}-p_{j}\right|<p^{T}$ for all $p$. For the trace gases, only the variability in the total columns was considered. The thresholds chosen for each parameter are given in Table 2. These values were chosen as the result of a compromise between the accuracy of the ADMs (see Fig. 4 for the justification) and the number of resulting scenes.

For the subsampling, the dissimilarity-based subset selection algorithm that was used is referred to as sphere-exclusion algorithm (Snarey et al. 1997) and works as follows:

TABLE 2. Median values of the initial subset for the different parameters and threshold considered in the dissimilarity-based selection algorithm.

\begin{tabular}{|c|c|c|c|c|c|c|c|c|c|c|}
\hline & $\mathrm{H}_{2} \mathrm{O}$ & $\mathrm{O}_{3}$ & $\mathrm{CO}$ & $\mathrm{CH}_{4}$ & $T_{s}$ & $T_{0}$ & $T_{5}$ & $T_{10}$ & $T_{15}$ & \\
\hline & \multicolumn{4}{|c|}{ Molecules $\mathrm{cm}^{-2}$ (total columns) } & \multicolumn{5}{|c|}{$\mathrm{K}$} & $\varepsilon_{s}$ \\
\hline Median & $7.12 \times 10^{22}$ & $7.34 \times 10^{18}$ & $1.45 \times 10^{18}$ & $3.72 \times 10^{19}$ & 292 & 292 & 267 & 232 & 205 & 0.989 \\
\hline Threshold & $8.90 \times 10^{21}$ & $1.83 \times 10^{18}$ & $7.25 \times 10^{17}$ & $1.86 \times 10^{19}$ & 4 & 4 & 4 & 4 & 4 & 0.025 \\
\hline
\end{tabular}




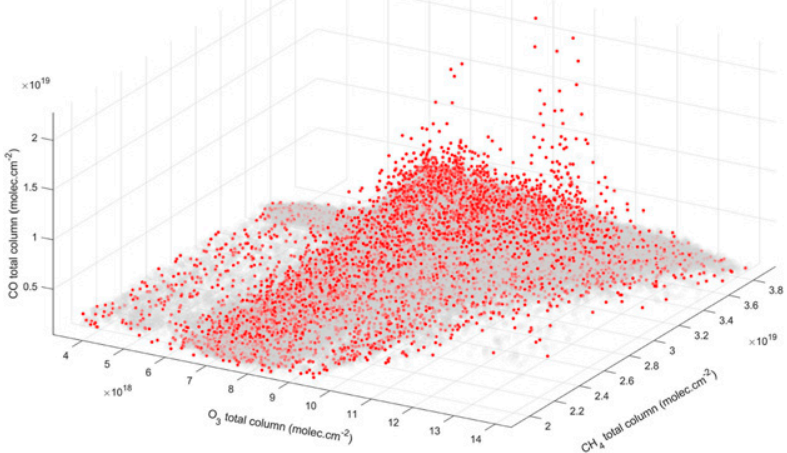

FIG. 3. Initial set (gray) and selected subset (red) of $\mathrm{O}_{3}, \mathrm{CO}$, and $\mathrm{CH}_{4}$ total columns from CAMS.

1) A scene type is randomly selected from the dataset.

2) All scene types in the dataset that have a dissimilarity with the selected scene type lower than the threshold $(T)$ are removed.

3) We return to step 1 until all scene types have a dissimilarity to each other higher than $T$ for all $p$.

To account for $\mathrm{CO}_{2}$ and $\mathrm{N}_{2} \mathrm{O}$ variable concentration in the atmosphere, each scene type in the subset was considered under three distinct $\mathrm{CO}_{2}(380,400,420 \mathrm{ppm})$ and two $\mathrm{N}_{2} \mathrm{O}(320,335 \mathrm{ppb})$ surface concentrations. These were chosen to cover the range of yearly average concentrations observed during the IASI period. $\mathrm{CO}_{2}$ surface concentrations were selected by looking at the globally averaged marine surface annual mean data provided by the National Oceanic and Atmospheric Administration Earth System Research Laboratory (NOAA/ESRL; https:// www.esrl.noaa.gov/gmd/ccgg). $\mathrm{N}_{2} \mathrm{O}$ surface concentrations were derived from global monthly mean data provided by the Advanced Global Atmospheric Gases Experiment (AGAGE; https://agage.mit.edu/data/ agage-data) (Prinn et al. 2018). We ended up with $23411 \times 3\left(\mathrm{CO}_{2}\right) \times 2\left(\mathrm{~N}_{2} \mathrm{O}\right)$ different scene types.

As an illustration, a representation of the subsampling is shown in Fig. 3 for three of the parameters: $\mathrm{O}_{3}, \mathrm{CO}$, and $\mathrm{CH}_{4}$. As expected, all the variability in the initial dataset is covered by the subset. Note that this dataset could also be of interest for other applications in atmospheric science (radiative transfer modeling, remote sensing, construction of ADMs for other hyperspectral instruments, etc.).
To assess the potential impact on the ADMs resulting from the choice of the thresholds, we calculated a set of $R_{s, \nu}(\theta)$ for a standard atmosphere (Table 3 ) from synthetic spectra simulated with the Atmosphit line-by-line radiative transfer code (Coheur et al. 2005) (using HITRAN2012 and MT-CKD 1.03). The simulation was then repeated but now the parameters were perturbed, one at a time, by their corresponding threshold value. $\mathrm{CO}_{2}$ and $\mathrm{N}_{2} \mathrm{O}$ were also included in the evaluation even though they were not taken into account for the selection of the scene types. For them, the variation was set to $20 \mathrm{ppm}$ and $15 \mathrm{ppb}$, respectively. The effect on the ADM is shown in Fig. 4 for a viewing zenith angle of $0^{\circ}$ $\left[\Delta R_{s, \nu}\left(0^{\circ}\right)\right]$. For all parameters, the relative difference is below $\pm 3 \%$. The portions of the spectrum affected depend on the region of absorption of the considered parameter. $\mathrm{O}_{3}$, for example, affects the $R_{s, \nu}$ mostly in its $\nu_{3}$ and in the $\nu_{1}+\nu_{3}$ absorption bands centered around 1042 and $2105 \mathrm{~cm}^{-1}$, respectively. In contrast, $\mathrm{H}_{2} \mathrm{O}$ impacts the $R_{s, \nu}$ in the region of its $\nu_{2}$ absorption band centered around $1595 \mathrm{~cm}^{-1}$ but also in the rest of the spectrum due to the influence of the water vapor continuum. The observations are similar for the other viewing angles (not shown here). The magnitude of these differences represents the worst case scenario. On average, the distance from an individual observation to the closest scene type is generally lower than the threshold value, and in addition, it can be expected that this type of random error averages out when observations are averaged in time or space. Indeed, a typical match results in distances another factor of 2 to 3 lower; that is, the standard deviation between the observations and the closest scene type in the ADM lookup table is on average 2 to 3 times lower than the threshold itself. This factor of 2 to 3 was calculated from 4 days of global observations (15 January, 15 April, 15 July, and 15 October of 2016). We also calculated the mean distance which turned out to be a factor 10 to 100 lower than the thresholds, indicating that individual biases cancel each other out on average.

\section{b. Construction of a table of spectral ADMs}

After the subset selection, an ADM needs to be derived for each of the selected scene types. We constructed these from synthetic spectra. For each scene, the corresponding spectral radiance $L_{\nu}(\theta)$ was simulated with the Atmosphit code for a set of chosen viewing

TABLE 3. Standard surface and atmospheric conditions.

\begin{tabular}{|c|c|c|c|c|c|c|c|c|c|c|c|}
\hline $\mathrm{H}_{2} \mathrm{O}$ & $\mathrm{O}_{3}$ & $\mathrm{CO}$ & $\mathrm{CH}_{4}$ & $\mathrm{CO}_{2}$ & $\mathrm{~N}_{2} \mathrm{O}$ & $T_{s}$ & $T_{0}$ & $T_{5}$ & $T_{10}$ & $T_{15}$ & \\
\hline \multicolumn{4}{|c|}{ Molecules $\mathrm{cm}^{-2}$ (total columns) } & \multicolumn{2}{|c|}{ Surface ppm } & \multicolumn{5}{|c|}{$\mathrm{K}$} & $\varepsilon_{s}$ \\
\hline $3.93 \times 10^{22}$ & $6.8 \times 10^{18}$ & $1.7 \times 10^{18}$ & $3.6 \times 10^{19}$ & 400 & 0.320 & 292 & 289 & 259 & 221 & 214 & 0.989 \\
\hline
\end{tabular}



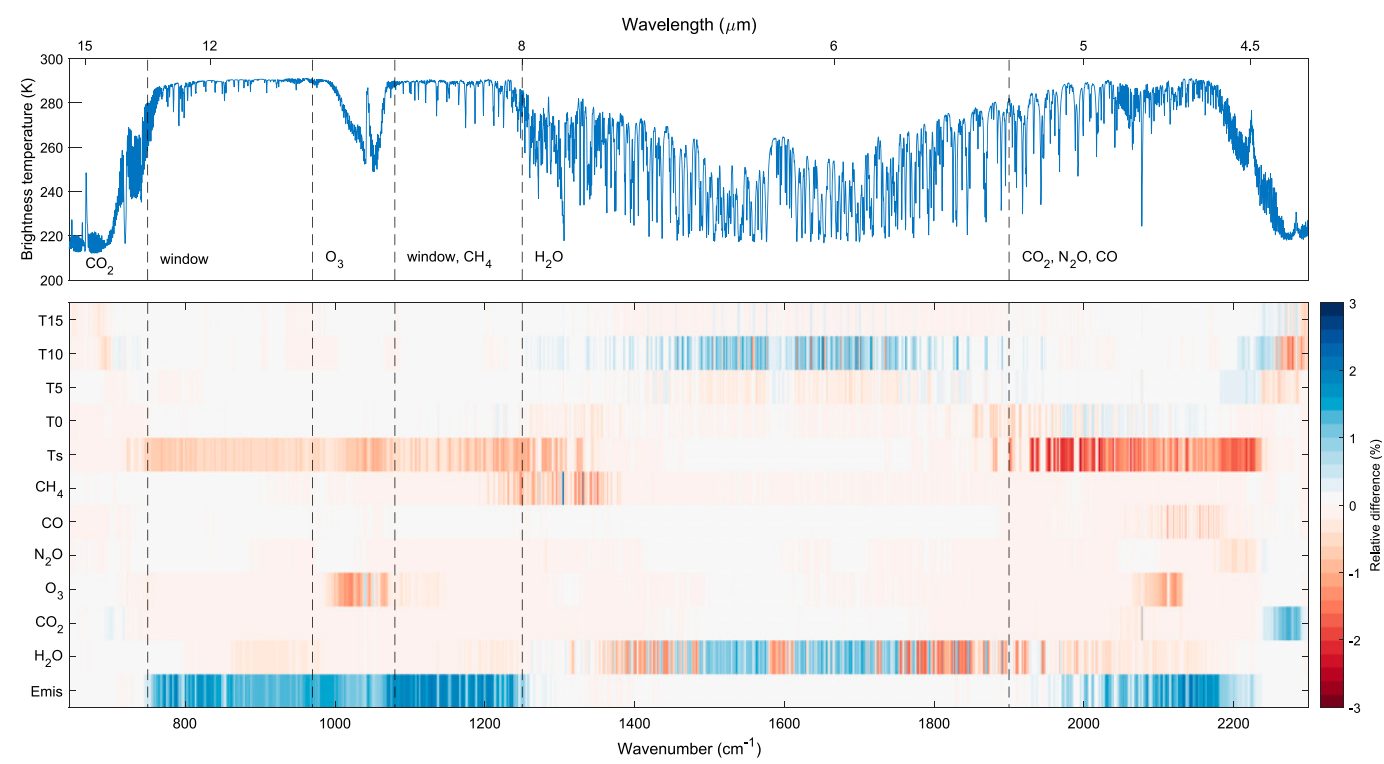

FIG. 4. (top) Example of an IASI spectrum. (bottom) Impact of atmospheric and surface parameters on $R_{s, \nu}\left(0^{\circ}\right)$. Relative difference (\%) between $R_{s, \nu}\left(0^{\circ}\right)$ calculated for a scene type characterized by standard surface and atmospheric conditions and for the same scene but varying the atmospheric and surface parameters one by one by the value of the threshold defined for all parameters.

zenith angles. From these spectra, $F_{\nu}$ was approximated using the Gaussian quadrature method where the integral is expressed as a weighted sum of $L_{\nu}\left(x_{i}\right)$ over a finite number $n$ of zenith angles $\theta$ (Li 2000; Doniki et al. 2015):

$$
F_{\nu}=2 \pi \int_{0}^{1} L_{\nu}(x) x d x \approx 2 \pi \sum_{i=1}^{n} \omega_{i} L_{\nu}\left(x_{i}\right),
$$

with the weights $\omega_{i}, x=\cos (\theta)$ and $d x=-\sin (\theta) d \theta$. Five angles $(n=5)$ were found to be sufficient for the value of $F_{\nu}$ integrated over the range $645-2300 \mathrm{~cm}^{-1}$ to reach a good approximation, with a difference of about $8.7 \times$ $10^{-3} \mathrm{~W} \mathrm{~m}^{-2}$ (less than $0.005 \%$ ) compared to $F_{\nu}$ calculated for $n=4$. The parameters $x_{i}$ and $\theta_{i}$ and weights $\omega_{i}$ are given in Table 4 . In addition, $L_{\nu}(\theta)$ was also systematically calculated for two extra angles corresponding to the nadir position $\left(\theta=0^{\circ}\right)$ and the maximum viewing angle of IASI $\left(\theta=58.4^{\circ}\right)$. While this was not needed for the calculation of $F_{\nu}$, their associated $R_{s, \nu}(\theta)$ [derived from Eq. (4)] will ensure an accurate interpolation of the ADMs at all IASI angles and avoid extrapolation for low angles (see hereafter). In total, $23411 \times 6 \times 7$ simulations were performed and used, with the corresponding estimated $F_{\nu}$, to build a lookup table (LUT) of ADMs following Eq. (4). Figure 5 shows an example of $R_{s, \nu}(\theta)$ for one of the selected scene type for the five angles considered in the simulations that are included in the range of IASI's viewing angles. At most wavenumbers, $R_{s, \nu}(\theta)$ decreases as viewing zenith angle increases (an effect known as "limb-darkening"), except in the regions corresponding to the $\nu_{2}$ and $\nu_{3} \mathrm{CO}_{2} \mathrm{ab}$ sorption bands (known as "limb-brightening") (Huang et al. 2008).

For the simulations, the vertical profiles were taken from CAMS. The use of the CAMS profiles rather than a constant profile for each species contributes to improve the accuracy in OLR restitution since each combination of parameters describing a scene is likely associated with a region and period of the year characterized by a given climatology. Surface spectral emissivities were taken from the 2014 monthly climatology provided by Zhou et al. (2011) (for land scenes) and Nalli et al. (2008) (for sea scenes). For $\mathrm{CO}_{2}$ and $\mathrm{N}_{2} \mathrm{O}$, standard modeled profiles based on latitude and season (Anderson et al. 1986) were used and scaled to match the three $\mathrm{CO}_{2}$ and two $\mathrm{N}_{2} \mathrm{O}$ surface concentrations.

The LUT of ADMs was finally interpolated at the yearly average $\mathrm{CO}_{2}$ and $\mathrm{N}_{2} \mathrm{O}$ surface concentrations

TABLE 4. Satellite zenith angle, cosine of zenith angle, and associated weights for five-angle Gaussian quadrature (Li 2000).

\begin{tabular}{ccc}
\hline \hline$\theta_{i}$ & $x_{i}=\cos \left(\theta_{i}\right)$ & Weights, $\omega_{i}$ \\
\hline 16.22 & 0.9602 & 0.0968 \\
36.68 & 0.8020 & 0.1672 \\
55.80 & 0.5620 & 0.1464 \\
72.27 & 0.3045 & 0.0739 \\
84.34 & 0.0985 & 0.0157 \\
\hline
\end{tabular}




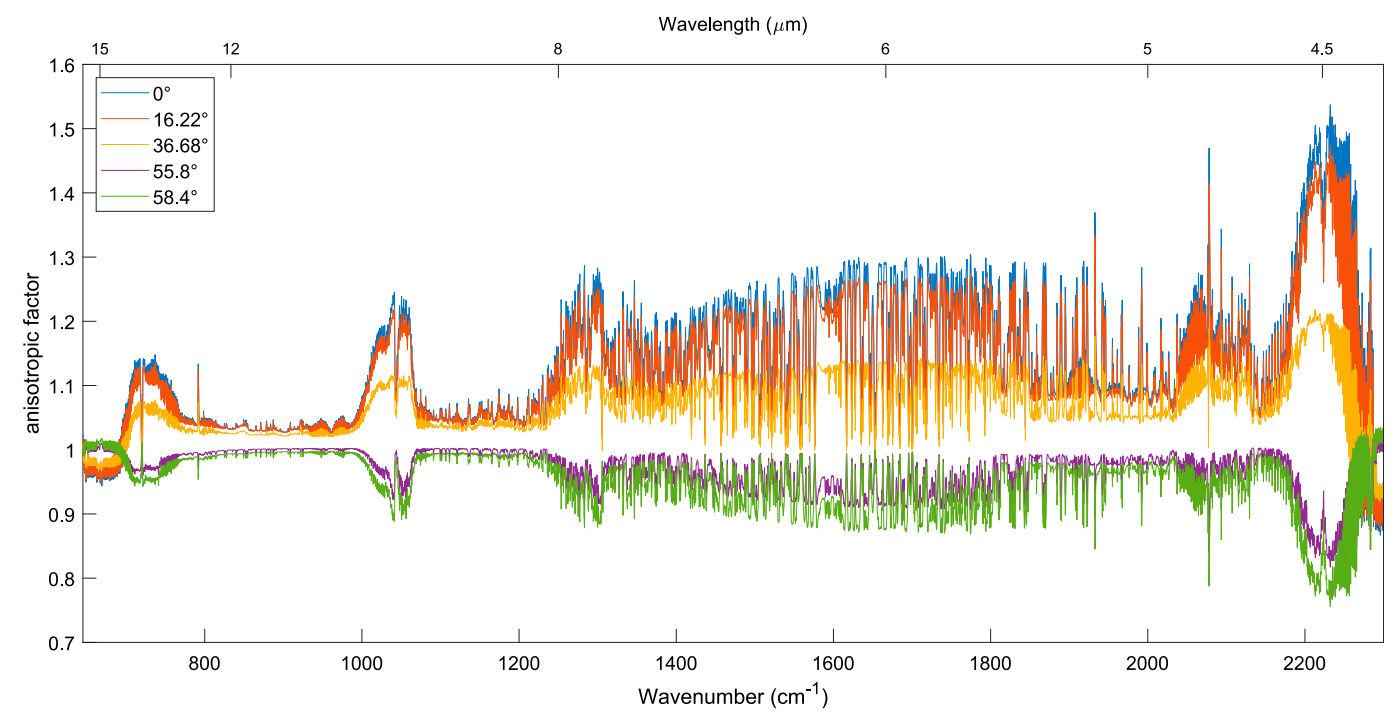

FIG. 5. Example of $R_{s, \nu}(\theta)$ for one of the selected scene type for the five angles considered in the simulations that are included in the range of IASI's viewing angles $\left(\theta=0^{\circ}, 16.22^{\circ}, 36.68^{\circ}, 55.80^{\circ}, 58.40^{\circ}\right)$.

(provided by NOAA/ESRL and AGAGE, respectively) between 2008 and 2017 and at the zenith angles of IASI. For the latter, we determined an average angle for each of the two pairs of pixels $(2 \times 2)$ that compose the 15 FOV of the track of IASI on either side of the nadir position. Because IASI's trace is symmetric on both sides of the nadir, 30 angles is enough to cover all situations. Considering these, the final dimensions of the LUT are 23411 (scenes) $\times 6621$ (IASI channels, up to $\left.2300 \mathrm{~cm}^{-1}\right) \times 30$ (angles) $\times 9\left(\right.$ yearly $\mathrm{CO}_{2}$ and $\left.\mathrm{N}_{2} \mathrm{O}\right)$.

\section{OLR estimation}

The actual estimation of OLR consists of applying the correct $R_{s, \nu}(\theta)$ to each IASI observed radiance $L_{\nu}(\theta)$ (L1C radiance spectra) to derive the spectral OLR $\left(F_{\nu}\right)$ (bottom box in Fig. 2). The retrieval is performed in four steps. L1C radiance spectra are first filtered out to select cloud-free scenes since our LUT of ADMs do not include cloud scene types. We rely for this on the cloud information derived from the Advanced Very High Resolution Radiometer (AVHRR) flying on board the MetOp satellites as well and directly provided in the IASI L1C datasets. The parameter (product GEUMAvhrr1BCldFrac) corresponds to the percentage of AVHRR pixels within the IASI footprint in which a cloud is detected (Guidard et al. 2011). All observations with a nonzero cloud fraction are filtered out (this leaves about $14 \%$ of all observations). For the remaining L1C radiance spectra, the different parameters describing the scene types are then gathered. For this, the closest $0.25^{\circ} \times 0.25^{\circ}$ CAMS grid cell is found and parameters are linearly interpolated to the IASI overpass time. Surface emissivities selection is identical as for the scene type selection and the simulations. From the CAMS parameters, the $R_{s, \nu}(\theta)$ associated with the closest scene type and interpolated for $\mathrm{CO}_{2}$ and $\mathrm{N}_{2} \mathrm{O}$ is selected next. If none of the scene types are found to be close enough, under the threshold conditions defined in section 2a, the L1C radiance spectra is ignored. This removes about 2000 IASI observations per day ( $\sim 1 \%$ of all cloud-free observations). The L1C radiance spectra are then converted to spectral OLR $F_{\nu}$ by application of the selected $R_{s, \nu}(\theta)$ [from Eq. (4)] and averaged on a $2^{\circ} \times 2^{\circ}$ grid.

To verify that our algorithm works correctly, we have derived the spectral OLR for each pixel of IASI for four days of measurements (15 January, 15 April, 15 July, and 15 October of 2016) and we have grouped them by scene type. We then calculated a mean $\operatorname{OLR}\left(\bar{F}_{s, \nu, \mathrm{IASI}}\right)$ for each scene type and compared with the corresponding synthetic OLR $\left(F_{s, \nu, \text { LUT }}\right)$ associated with the ADMs (thus derived from the forward simulations). Figure 6 shows the mean and the standard deviation of the differences between $\bar{F}_{s, \nu, \text { IASI }}$ and corresponding $F_{S, \nu, \text { LUT }}$ on all represented scene types (about 4000 on the four days). Differences are generally within $\pm 0.005 \mathrm{~W} \mathrm{~m}^{-2}\left(\mathrm{~cm}^{-1}\right)^{-1}$ (maximum $3 \mathrm{~K}$ in brightness temperature) for all wavenumbers, except for one IASI stratospheric sensitive channel corresponding to the $Q$ branch of the $\nu_{2} \mathrm{CO}_{2}$ absorption band. This larger difference cannot be explained only by the consideration of a single average $\mathrm{CO}_{2}$ concentration per year-therefore not taking into account the local variations and seasonality-and likely 


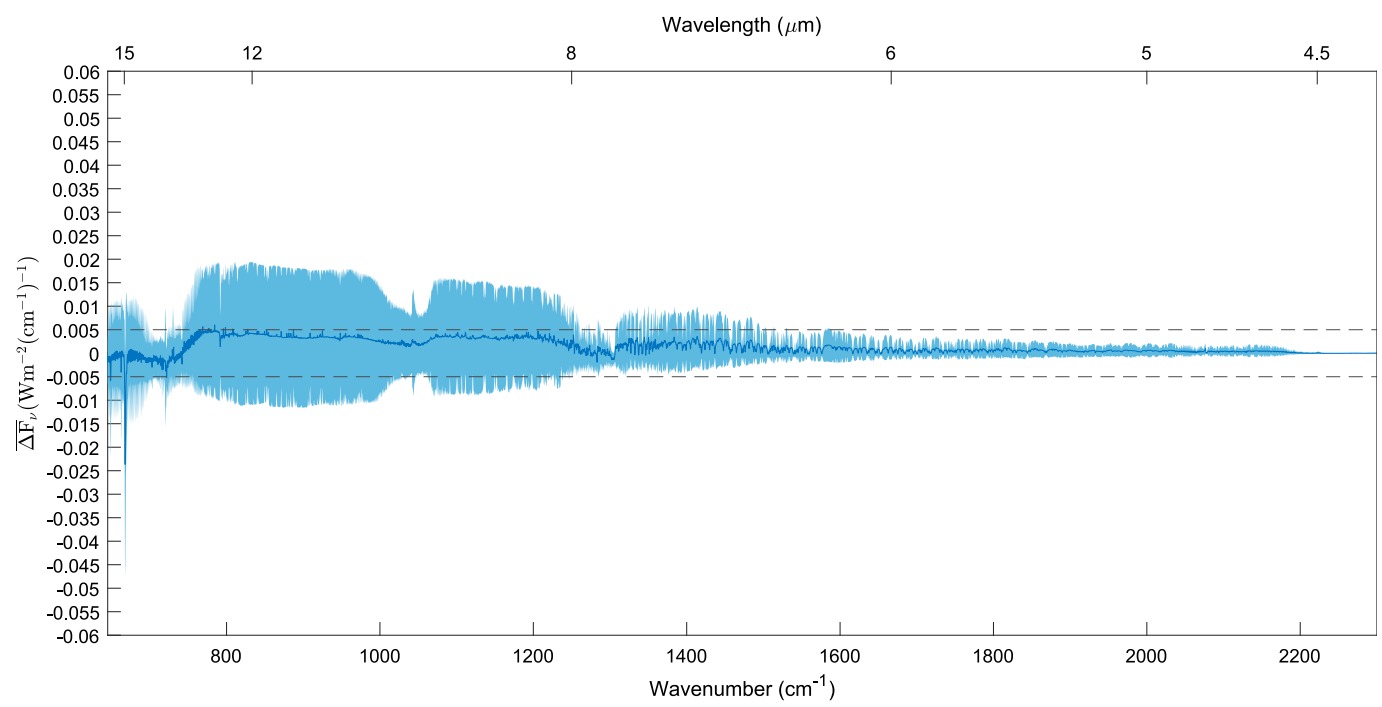

FIG. 6. Mean (blue line) and standard deviation (shaded area) of the differences between the mean OLR of each scene type represented in four days of IASI observations (15 Jan, $15 \mathrm{Apr}, 15 \mathrm{Jul}$, and 15 Oct 2016) and the corresponding synthetic OLRs from the LUT of ADMs.

reflects a problem with the Atmosphit radiative transfer code for this strong $Q$ branch. Very close agreement elsewhere else indicates that, despite remaining uncertainties on the other surface and atmospheric parameters and that trace gases in the scene types are only characterized by atmospheric total columns while vertical profiles were considered in the simulations, the algorithm can estimate the flux with a good precision at the spectral sampling of $0.25 \mathrm{~cm}^{-1}$. This result supports the representativeness of the $23411 \times 6$ different scene types selected that appear to be enough to characterize with a good precision all the climatology encountered on Earth. Note that the observed differences between $\bar{F}_{s, \nu, \text { IASI }}$ and $F_{s, \nu \text { LUT }}$ do not indicate an equivalent bias on the IASIderived OLR as the impact of these differences on the ADM is much lower (see Fig. 4).

An example of mean seasonal OLR $\left(\mathrm{Wm}^{-2}\right)$ for the morning overpasses of the year 2016 is given in Fig. 7. For the representation, the spectral OLR $\left[\mathrm{W} \mathrm{m}^{-2}\left(\mathrm{~cm}^{-1}\right)^{-1}\right]$ was integrated over the spectral range between 645 and
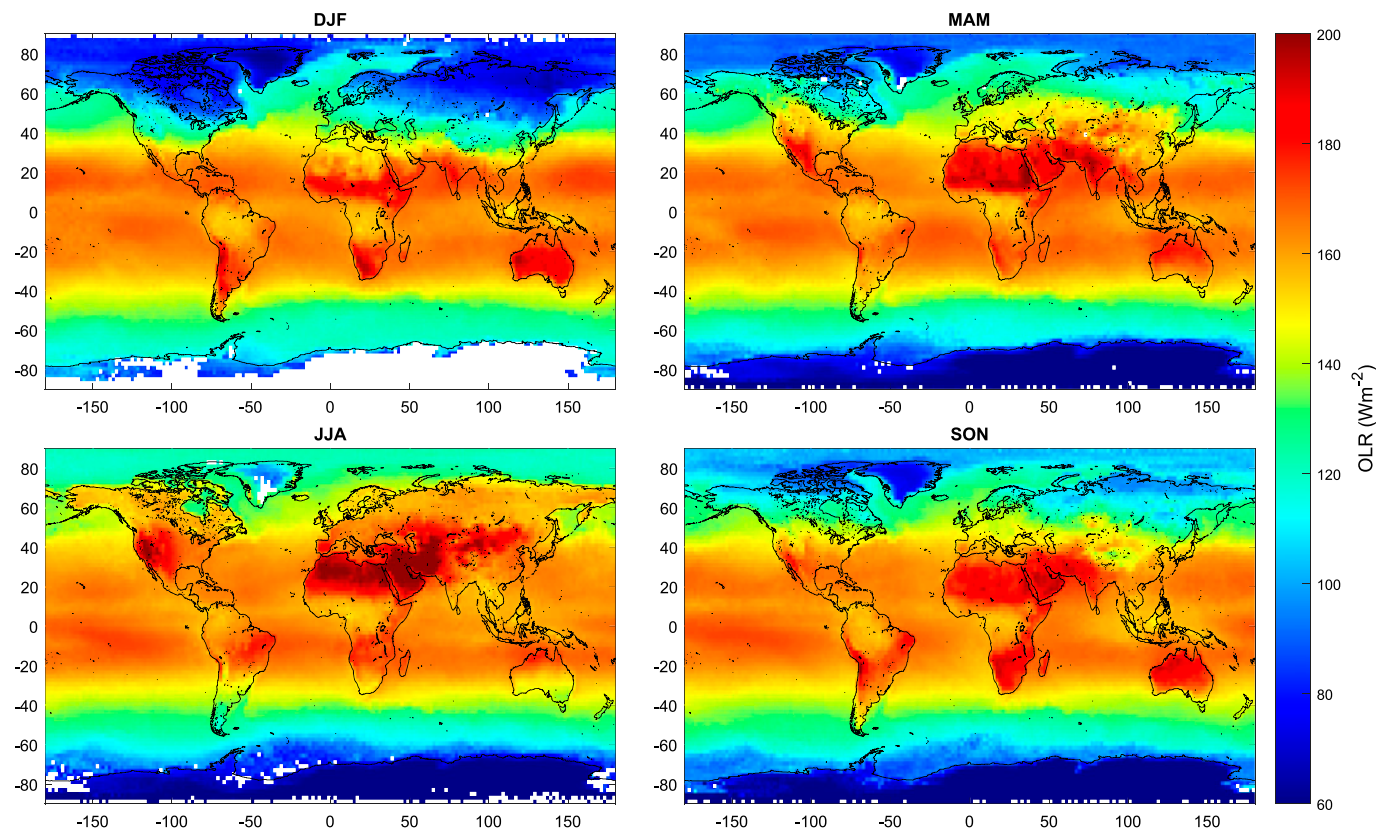

FIG. 7. Average seasonal integrated OLR $\left(645-2300 \mathrm{~cm}^{-1} ; \mathrm{W} \mathrm{m}^{-2}\right)$ for the year 2016 (morning overpass) derived
from IASI measurements: (top left) DJF, (top right) MAM, (bottom left) JJA, and (bottom right) SON. 

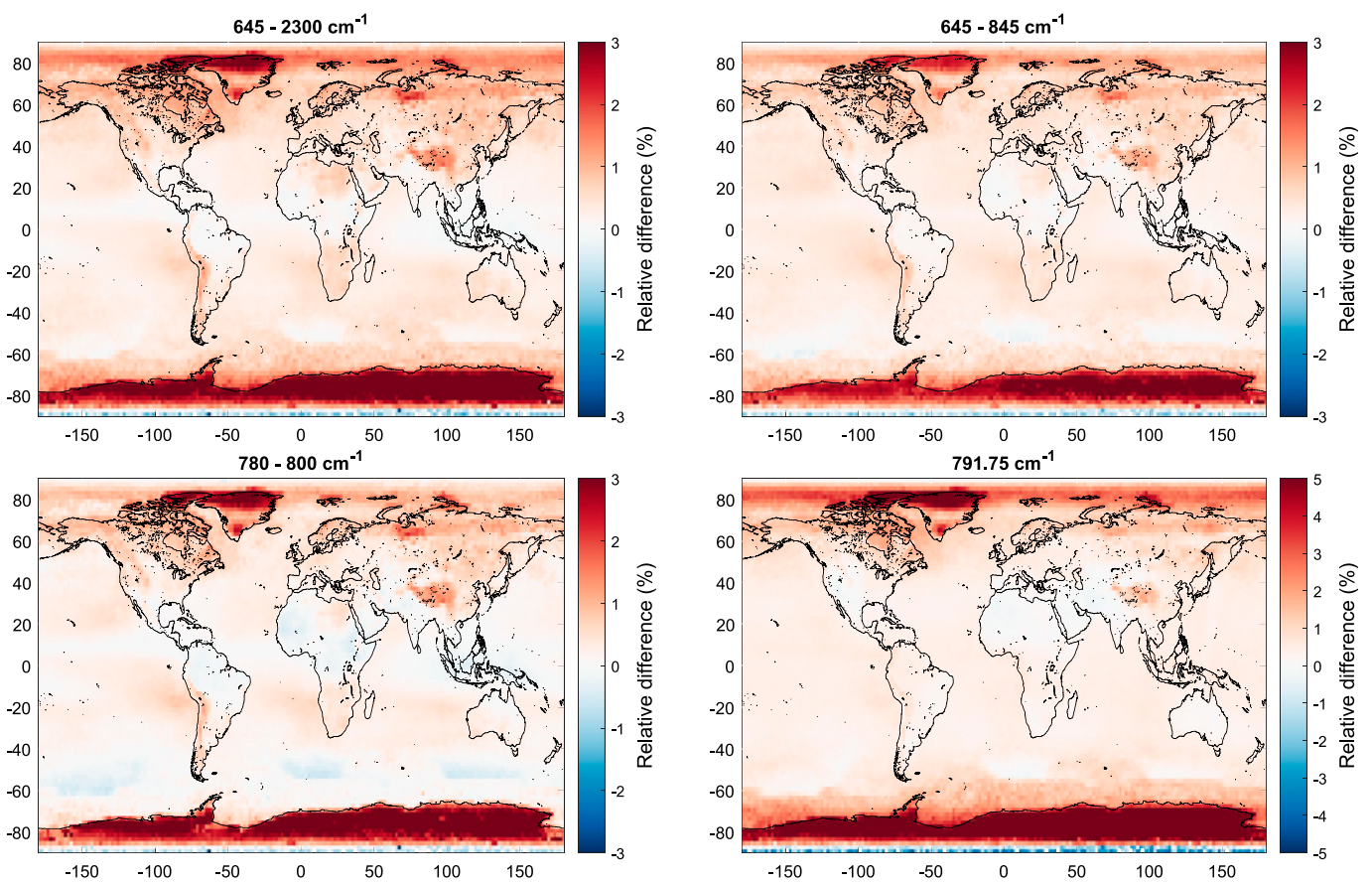

FIG. 8. Annual mean relative difference (\%) for the year 2016 between integrated IASI OLR derived using the LUT of ADMs and derived from a constant ADM corresponding to standard surface and atmospheric conditions: $\left(\mathrm{OLR}_{\mathrm{LUT}}-\mathrm{OLR}_{\mathrm{std}}\right) / \mathrm{OLR}_{\text {std }}$. Spectral OLR integrated over the (top left) $645-2300 \mathrm{~cm}^{-1}$ spectral range, (top right) $645-845 \mathrm{~cm}^{-1}$, (bottom left) $780-800 \mathrm{~cm}^{-1}$, and (bottom right) $791.75 \mathrm{~cm}^{-1}$.

$2300 \mathrm{~cm}^{-1}$. A clear seasonality is observed above land, especially in the Northern Hemisphere. To assess the importance of considering scene type-dependent ADMs in the calculation of spectral OLR, we calculated the mean relative difference ( $\%$ ) for the year 2016 between IASI OLR derived using our LUT of ADMs and using a constant ADM corresponding to standard surface and atmospheric conditions (Table 3 ). The impact was evaluated for four different spectral ranges: 1) the full 645$2300 \mathrm{~cm}^{-1}$ band considered in the retrieval, 2) between 645 and $845 \mathrm{~cm}^{-1}$ mainly affected by $\mathrm{CO}_{2}$ absorption, 3) between 780 and $800 \mathrm{~cm}^{-1}$, and 4) for a $\mathrm{CO}_{2}$-sensitive channel at $791.75 \mathrm{~cm}^{-1}$. Results are shown in Fig. 8. The largest differences are found above land in the Northern Hemisphere and at the poles. This reflects the increasing differences between the standard atmosphere and the actual state of the atmosphere as we move toward the poles. For the complete $645-2300 \mathrm{~cm}^{-1}$ spectral range, relative differences are lower than $0.5 \%$ in the intertropical region. The differences increase to $1 \%-1.5 \%$ over the region corresponding globally to Russia and China, and over Canada and reach more than 3\% above Greenland and Antarctica. When analyzing integrated fluxes on narrower bands, the differences increase. These reach $2 \%-3 \%$ above China and Russia and more than $5 \%$ at the poles for the channel at $791.75 \mathrm{~cm}^{-1}$.

\section{Comparison with CERES and AIRS integrated OLR}

In this section, we compare the mean integrated IASI OLR to the OLR produced by the CERES and AIRS Science Teams. The CERES instruments measure radiances in the shortwave (SW; between 0.3 and $5 \mu \mathrm{m}$ ), total (TOT; between 0.3 and $200 \mu \mathrm{m}$ ) and window (between 8 and $12 \mu \mathrm{m}$ ) infrared regions. Because CERES does not include a dedicated LW detector, LW radiances are determined from the TOT and the SW channels and correspond to the band $50-2000 \mathrm{~cm}^{-1}$ (5$200 \mu \mathrm{m})$. The CERES Science Team generates several different OLR datasets. The product considered here is the latest version of the CERES level-3 Energy Balanced and Filled (EBAF) Edition 4.0 (Loeb et al. 2018). It is built using combined measurements from CERES on Terra and Aqua (after 2002) with the latest edition-4 instrument calibration, cloud properties and ADMs improvements and consists of monthly mean clear-sky and all-sky TOA flux maps on a $1^{\circ} \times 1^{\circ}$ grid. The monthly averages are obtained by temporally interpolating observed values at $1-\mathrm{h}$ increments, and then by averaging all hour boxes in a month (Loeb et al. 2018). For the AIRS Science Team OLR, we used the latest version (version 6) of the daily mean AIRS 

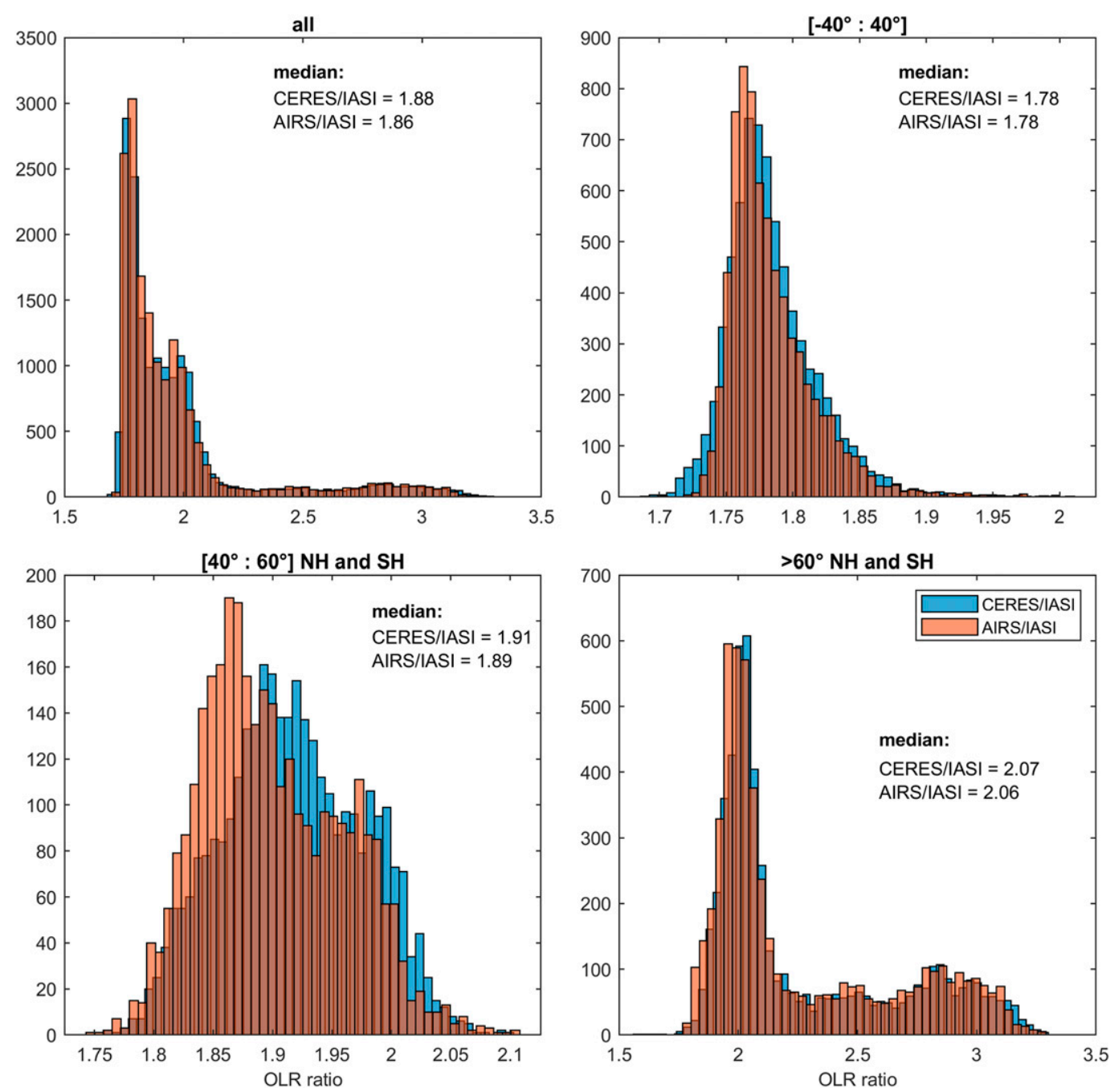

FIG. 9. Histogram of the ratio of the OLR derived from CERES EBAF (Terra + Aqua) (blue) and from the AIRS L3 V6 Science Team (average between 0130 and 1330 LT overpass) (red) against the OLR derived from IASI from the 2016 yearly averaged $2^{\circ} \times 2^{\circ}$ grid of integrated OLR (average between 0930 and 2130 LT overpass), shown (a) for the entire globe, (b) for the intertropical regions (between $-40^{\circ}$ and $40^{\circ}$ latitude), (c) for temperate regions (between $40^{\circ}$ and $60^{\circ}$ Northern and Southern Hemisphere), and (d) at latitudes higher than $60^{\circ}$.

Level-3 product distributed on a $1^{\circ} \times 1^{\circ}$ grid (Susskind et al. 2014). It is computed as a function of atmospheric and surface conditions retrieved from AIRS measurements (see Table 1). As for CERES, both clear-sky and all-sky OLR are provided (separately for AM and PM orbits). Since our retrieval algorithm was developed for cloud-free scenes, the comparison is done here with clearsky LW fluxes from AIRS and CERES. Note that the intent here is not to validate the IASI-derived spectrally resolved OLR through the comparison with CERES and AIRS broadband OLR, but rather to give an insight of how it compares with other satellite-derived OLR products.

For the comparison, we first computed the ratio of CERES EBAF and AIRS OLR L3 V6 to IASI integrated
OLR averaged over the year 2016 on a $2^{\circ} \times 2^{\circ}$ grid. For the averaging, morning and evening overpasses (at around 0930 and 2130 LT) were first computed separately for IASI and then averaged together. The same procedure was applied to the AIRS OLR to average the ascending and descending orbits (at around 0130 and 1330 LT). Figure 9 shows the frequency histograms of the ratio CERES/IASI and AIRS/IASI OLR for different bands of latitude. In general, both AIRS and CERES OLR show about a factor of 1.7-3.0 higher than IASI OLR due to the fact that IASI OLR is here integrated from $645 \mathrm{~cm}^{-1}$ while AIRS and CERES OLR cover the whole LW spectral range. This is well within the range of previous studies investigating the contribution of far infrared 


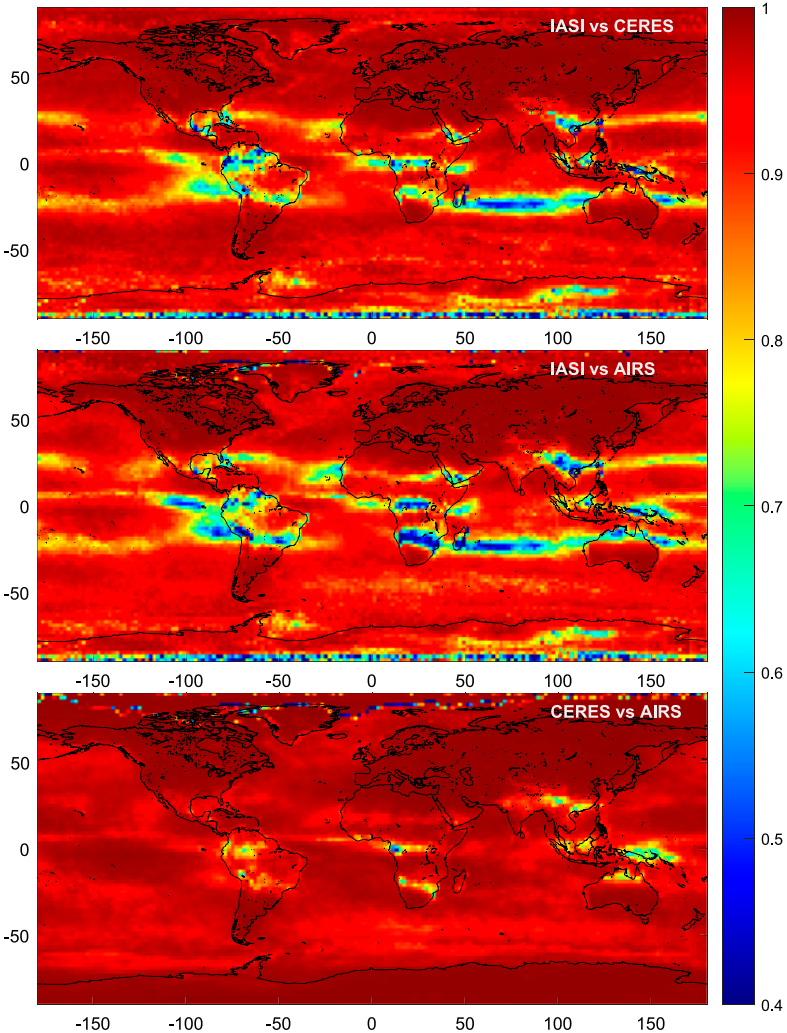

FIG. 10. Correlation coefficient $(R)$ of (top) the monthly mean IASI (average between 0930 and 2130 LT overpass) vs CERES EBAF (Terra + Aqua) OLR, (middle) IASI vs AIRS L3 V6 Science Team OLR (average between 0130 and 1330 LT overpass), and (bottom) CERES vs AIRS OLR in $2^{\circ} \times 2^{\circ}$ cells from 2012 to 2016 .

(FIR) to the total LW radiance (Harries et al. 2008; Turner et al. 2015). For tropical regions (between $-40^{\circ}$ and $40^{\circ}$ ), the ratios are generally close to the median value of 1.8, in good agreement with Turner et al. (2015). The low variability indicates that IASI reproduces very well the spatial variability in OLR as produced by AIRS and CERES. Beyond $40^{\circ}$ latitude, the contribution of FIR increases as temperature falls (Turner et al. 2015). The ratio increases progressively as we move toward the poles with values between 1.7 and 2.1 for temperate regions (median of about 1.9) and between 1.75 and 3.25 for polar regions (median of about 2.1). We calculated also the correlation coefficient $(R)$ between the monthly means of the pairs IASI-CERES, IASI-AIRS, and CERES-AIRS OLR from 2012 to 2016 on a $2^{\circ} \times 2^{\circ}$ grid (Fig. 10). Overall, a strong correlation is found between IASI, CERES, and AIRS with an $R$ higher than 0.9. For some regions between $-30^{\circ}$ and $30^{\circ}$ latitude, however, a lower correlation $(R=0.4-0.7)$ is observed between the three pairs of OLR. Above sea, the correspondence is generally better between CERES and AIRS OLR than with IASI OLR. This could be partly explained by a wrong evaluation of the cloud-free scenes in the AVHRR cloud product or biases in the CAMS reanalysis dataset for some of the IASI observations. Because the seasonality (variability) of the OLR is lower in the tropical regions compared to what exists at higher latitudes, the impact of such error and biases in these regions is more important. Another possible explanation could be that part of the variability in the whole LW integrated OLR is not available in the IASI derived OLR integrated from $645 \mathrm{~cm}^{-1}$. In contrast, at high latitudes around the North Pole, the correlation between IASI and CERES derived OLR is better than between AIRS and CERES. This could reflect a bias in the atmospheric and surface parameters retrieved from the AIRS measurements and used to compute the OLR.

\section{Comparison with spectrally resolved AIRS OLR}

The IASI-derived OLR product is most interesting when it is considered in its spectrally resolved form. We provide here a comparison with the spectrally resolved OLR derived from the AIRS measurements by Huang et al. and Chen et al. (Huang et al. 2008; X. Huang et al. 2010a; Chen et al. 2013; Huang et al. 2014; Chen and Huang 2016). The product is distributed on the form of monthly-mean averages at a spatial resolution of $2.5^{\circ}$ longitude by $2^{\circ}$ latitude and with a spectral interval of $10 \mathrm{~cm}^{-1}$ in the range $10-2000 \mathrm{~cm}^{-1}$. Both clear-sky and all-sky OLR are provided for the period 2002-15. As for the comparison with integrated AIRS and CERES OLR, only the clear-sky OLR is considered here.

To ease the comparison with AIRS spectral OLR, the $2^{\circ} \times 2^{\circ}$ daily IASI OLR grids were first averaged by months and integrated at a spectral resolution of $10 \mathrm{~cm}^{-1}$. Monthly mean IASI and AIRS spectral OLR were then averaged by latitude band, separately for land and ocean and for day and night observations. The analysis is detailed here for the tropical region (between $-30^{\circ}$ and $30^{\circ}$ of latitude) for June 2015 but is also valid for the other periods and regions. Results are shown in Fig. 11. A first interesting feature to notice is the additional information brought by a higher spectral resolution of $0.25 \mathrm{~cm}^{-1}$ (blue line), which makes the spectral signature of a series of atmospheric trace gases appear and allows to evaluate their impact individually on the OLR. The comparison between AIRS and IASI OLR integrated at a spectral resolution of $10 \mathrm{~cm}^{-1}$ shows a very good correspondence outside the atmospheric window, with differences (Fig. 11, right panels) of about $0.01-0.02 \mathrm{~W} \mathrm{~m}^{-2}\left(10 \mathrm{~cm}^{-1}\right)^{-1}$ on average in the region of absorption of $\mathrm{H}_{2} \mathrm{O}$ (after $1250 \mathrm{~cm}^{-1}$ ) and of about $0.02-$ $0.05 \mathrm{~W} \mathrm{~m}^{-2}\left(10 \mathrm{~cm}^{-1}\right)^{-1}$ in the $\mathrm{CO}_{2}$ and $\mathrm{O}_{3}$ absorption bands (below $750 \mathrm{~cm}^{-1}$ and between 970 and $1070 \mathrm{~cm}^{-1}$, 

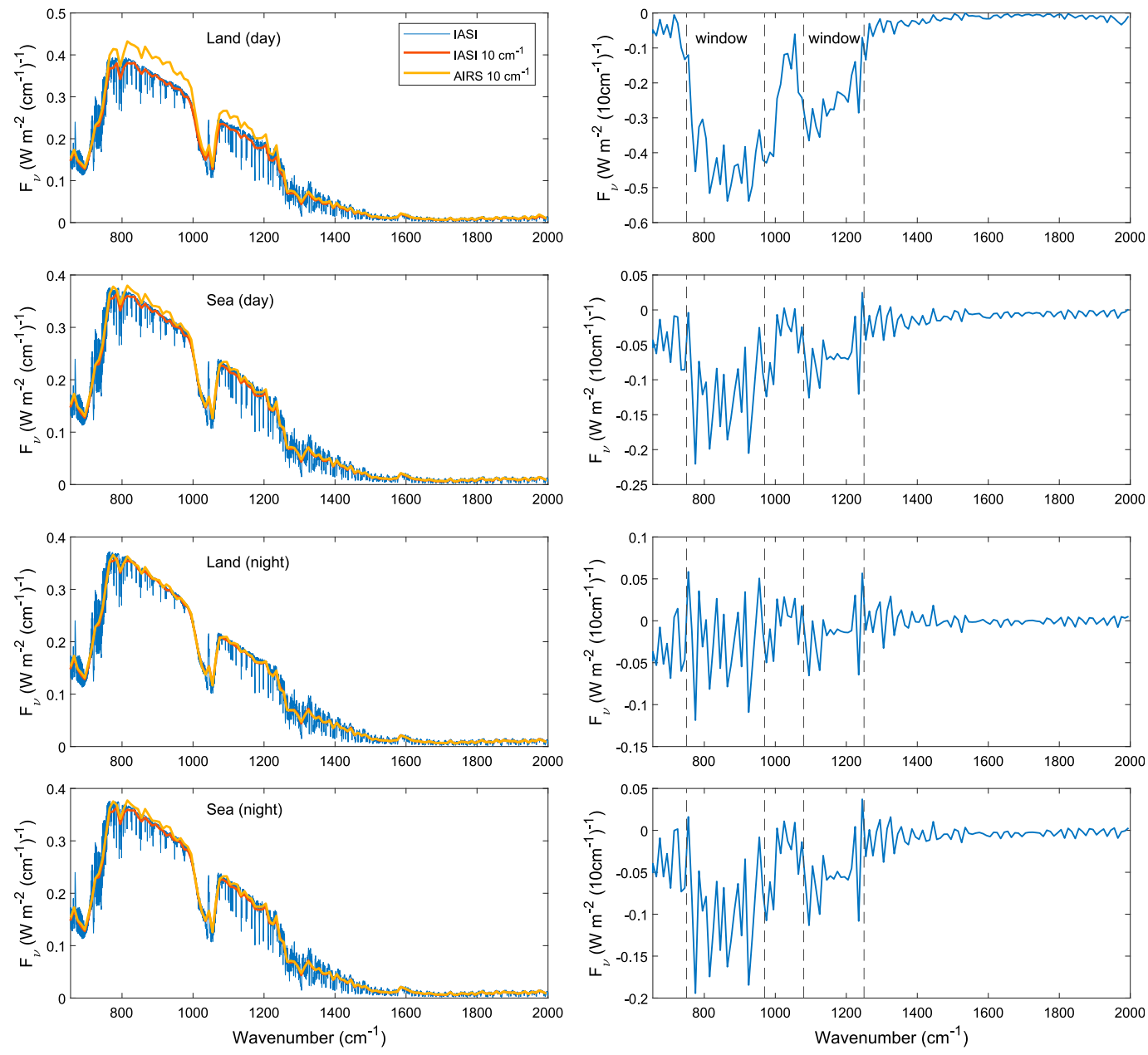

FIG. 11. (left) Monthly mean IASI (red) and AIRS (yellow) OLR for June 2015 for the tropical regions at a spectral resolution of $10 \mathrm{~cm}^{-1}$, separately for (from top to bottom) daytime land, daytime sea, nighttime land, and nighttime sea observations. The corresponding IASI derived OLR at the spectral resolution of $0.25 \mathrm{~cm}^{-1}$ is shown in blue. For the representation, integrated IASI and AIRS OLR at $10 \mathrm{~cm}^{-1}$ were divided by 10 to match with IASI OLR at $0.25 \mathrm{~cm}^{-1}$. (right) Difference between IASI and AIRS derived OLR.

respectively). This gives a good confidence in the ability of our retrieval algorithm to produce accurate spectrally resolved IASI derived OLR. In the atmospheric window, the differences are larger with AIRS OLR being systematically higher than IASI. This was expected for daytime observations because of the higher surface temperature at the overpass time of AIRS (1330 LT) compared to IASI (0930 LT), in particular for land measurements which is characterized by a stronger diurnal cycle of the surface temperature than oceans (Smith and Rutan 2003; Comer et al. 2007; Gristey et al. 2018). For seas however, these differences seem too high to be explained by the diurnal cycle only (limited to $\sim 0.4 \mathrm{~K}$ in the tropics; Yang et al. 2015). Moreover, for nighttime observations, while the differences between IASI and AIRS are lower, AIRS OLR remains systematically higher than IASI despite a slightly lower surface temperature at the overpass time of AIRS ( $0130 \mathrm{vs} 2130 \mathrm{LT}$ for IASI) (Yang et al. 2015). At this point, the origin of these differences is unclear. One possible explanation could be that the AVHRR cloud flag might not be as conservative as the cloud flag used for AIRS, leaving some observations with a small amount of cloud. However, this is unlikely to be the main reason.

\section{Conclusions}

In this paper, we have presented a new algorithm for the retrieval of spectrally resolved OLR from IASI satellite measurements for clear-sky observations. IASI is particularly well suited for the analysis of spectrally resolved OLR since it combines a good spatial coverage 
to excellent instrumental performances, including a large and continuous coverage of the thermal infrared spectral range and a good calibration. The method is based on the use of a lookup table (LUT) of ADMs for the conversion of the spectral radiance to OLR. For the construction of the ADMs, a subset of representative scene types for the main surface and atmospheric parameters affecting the OLR is first selected from a large dataset of CAMS reanalysis. For each of them, an ADM was calculated by simulating the corresponding synthetic radiance spectrum under different viewing zenith angles. The actual retrieval of OLR from IASI observations is obtained by applying the ADM corresponding to the closest scene type to the measured radiance. The method is fast as the conversion relies on a precomputed LUT of ADMs. It is also accurate as most of the dependencies on the parameters affecting the OLR are taken into account.

Different illustrations of our retrieval algorithm are provided. These include an assessment of the importance of considering scene dependent ADMs compared to a single constant ADM. Results show significant differences on a yearly average, especially when considering OLR integrated on limited spectral bands with differences up to $5 \%$. The comparison of the IASI OLR integrated over the full $645-2300 \mathrm{~cm}^{-1}$ spectral range with the OLR produced by the CERES and AIRS Science Teams showed a good correspondence, with a correlation coefficient of the monthly means generally higher than 0.9. For some regions in tropical latitudes, however, a lower correlation $(R=0.4-0.7)$ was observed, possibly due to an inaccurate evaluation of the cloud-free scenes in the AVHRR cloud product or biases in the CAMS reanalysis dataset. Finally, the comparison of the IASI OLR with the spectral OLR derived from the AIRS observations (Huang et al. 2008; X. Huang et al. 2010; Chen et al. 2013; Huang et al. 2014; Chen and Huang 2016) showed an excellent agreement above $1200 \mathrm{~cm}^{-1}$, giving confidence in our algorithm to deliver spectrally resolved OLR with a good accuracy. In the atmospheric window region, the AIRS derived OLR appeared to be systematically higher, likely due to the differences in the overpass time of IASI and AIRS or to the different cloud filter used.

Since the first dissemination of L1C data in 2007 by EUMETSAT, a series of updates have been released affecting the consistency of the time record. In spring 2018, EUMETSAT released a complete reprocessed dataset of radiances (from the start of the IASI mission) with the latest version of the $\mathrm{L} 1 \mathrm{C}$, which allows us to produce consistent time series of $F_{\nu}$ over more than 10 years of IASI observations. Moreover, with the recent launch of IASI on MetOp-C (November 2018) and the future launch of IASI-NG (New Generation) on board the three MetOp-SG-A platforms (Crevoisier et al. 2014) planned for 2022, at least another 25 years of measurements is ensured. This dataset of spectrally resolved OLR can already be used for the analysis of trends in the spectral ranges of major climate gases (e.g., $\mathrm{CO}_{2}, \mathrm{CH}_{4}$ ) and of weaker absorbers (such as CFCs). Another major use case includes the identification of biases and errors in climate models that might not systematically appear in integrated fluxes derived from broadband observations.

Acknowledgments. IASI has been developed and built under the responsibility of the Centre National d'Études spatiales (CNES, France). It is flown on board the MetOp satellites as part of the EUMETSAT Polar System. This project has received funding from the European Research Council (ERC) under the European Union's Horizon 2020 research and innovation program (Grant Agreement 742909). It was also supported by the Prodex arrangement IASI.FLOW (Belspo-ESA). Simon Whitburn is grateful to the ERC for funding his research work. L. Clarisse and S. Bauduin are, respectively, Research Associate (Chercheur Qualifié) and Chargée de Recherche with the Belgian F.R.S.-FNRS. C. Clerbaux is grateful to CNES for scientific collaboration and financial support. We thank EUMETSAT for providing us a full reprocessed dataset of radiances with the latest version of the $\mathrm{L} 1 \mathrm{C}$. We also thank the CAMS, AGAGE, and NOAA/ESRL teams for the production and the distribution of the data used in this paper. We thank Professor X. Huang for the distribution of the spectrally resolved OLR dataset derived from AIRS measurements.

\section{REFERENCES}

Allan, R., and M. Ringer, 2003: Inconsistencies between satellite estimates of longwave cloud forcing and dynamical fields from reanalyses. Geophys. Res. Lett., 30, 1491, https://doi.org/ 10.1029/2003GL017019.

Anderson, B. T., J. R. Knight, M. A. Ringer, C. Deser, A. S. Phillips, J.-H. Yoon, and A. Cherchi, 2010: Climate forcings and climate sensitivities diagnosed from atmospheric global circulation models. Climate Dyn., 35, 1461-1475, https:// doi.org/10.1007/s00382-010-0798-y.

Anderson, G., S. Clough, F. Kneizys, J. Chetwynd, and E. Shettle, 1986: AFGL atmospheric constituent profiles $(0-120 \mathrm{~km})$. AFGL Tech. Rep. AFGL-TR-86-0110, 43 pp., https://apps.dtic.mil/dtic/ tr/fulltext/u2/a175173.pdf.

Aumann, H. H., and Coauthors, 2003: AIRS/AMSU/HSB on the Aqua mission: Design, science objectives, data products, and processing systems. IEEE Trans. Geosci. Remote Sens., 41, 253-264, https://doi.org/10.1109/TGRS.2002.808356.

Bantges, R. J., H. E. Brindley, X. H. Chen, X. L. Huang, J. E. Harries, and J. E. Murray, 2016: On the detection of robust multidecadal changes in Earth's outgoing longwave radiation spectrum. J. Climate, 29, 4939-4947, https://doi.org/10.1175/ JCLI-D-15-0713.1. 
Barkstrom, B. R., 1984: The Earth Radiation Budget Experiment (ERBE). Bull. Amer. Meteor. Soc., 65, 1170-1185, https:// doi.org/10.1175/1520-0477(1984)065<1170:TERBE>2.0.CO;2.

—, and G. L. Smith, 1986: The Earth Radiation Budget Experiment: Science and implementation. Rev. Geophys., 24, 379, https://doi.org/10.1029/RG024i002p00379.

Barlow, M., M. Wheeler, B. Lyon, and H. Cullen, 2005: Modulation of daily precipitation over Southwest Asia by the MaddenJulian oscillation. Mon. Wea. Rev., 133, 3579-3594, https:// doi.org/10.1175/MWR3026.1.

Bertrand, C. P., D. Caprion, N. Clerbaux, S. Dewitte, L. Gonzalez, and A. Ipe, 2004: First TOA fluxes from the Geostationary Earth Radiation Budget (GERB) instrument. Proc. SPIE, 5571, https://doi.org/10.1117/12.563305.

Brindley, H., R. Bantges, J. Russell, J. Murray, C. Dancel, C. Belotti, and J. Harries, 2015: Spectral signatures of Earth's climate variability over 5 years from IASI. J. Climate, 28, 1649-1660, https://doi.org/10.1175/JCLI-D-14-00431.1.

Chen, X., and X. Huang, 2016: Deriving clear-sky longwave spectral flux from spaceborne hyperspectral radiance measurements: A case study with AIRS observations. Atmos. Meas. Tech., 9, 6013-6023, https://doi.org/10.5194/amt-96013-2016.

, — - N. G. Loeb, and H. Wei, 2013: Comparisons of clear-sky outgoing far-IR flux inferred from satellite observations and computed from the three most recent reanalysis products. J. Climate, 26, 478-494, https://doi.org/10.1175/JCLI-D-1200212.1.

Chiodi, A. M., and D. E. Harrison, 2010: Characterizing warm-ENSO variability in the equatorial Pacific: An OLR perspective. J. Climate, 23, 2428-2439, https://doi.org/10.1175/2009JCLI3030.1.

Chu, P.-S., and J.-B. Wang, 1997: Recent climate change in the tropical western Pacific and Indian Ocean regions as detected by outgoing longwave radiation records. J. Climate, 10, 636-646, https:// doi.org/10.1175/1520-0442(1997)010<0636:RCCITT>2.0.CO;2.

Chung, E.-S., D. Yeomans, and B. J. Soden, 2010: An assessment of climate feedback processes using satellite observations of clear-sky OLR. Geophys. Res. Lett., 37, L02702, https:// doi.org/10.1029/2009GL041889.

Clement, A. C., and B. Soden, 2005: The sensitivity of the tropicalmean radiation budget. J. Climate, 18, 3189-3203, https:// doi.org/10.1175/JCLI3456.1.

Clerbaux, C., and Coauthors, 2009: Monitoring of atmospheric composition using the thermal infrared IASI/MetOp sounder. Atmos. Chem. Phys., 9, 6041-6054, https://doi.org/10.5194/ acp-9-6041-2009.

Clerbaux, N., S. Dewitte, L. Gonzalez, C. Bertrand, B. Nicula, and A. Ipe, 2003: Outgoing longwave flux estimation: Improvement of angular modelling using spectral information. Remote Sens. Environ., 85, 389-395, https://doi.org/10.1016/S0034-4257(03)00015-4.

Coheur, P.-F., B. Barret, S. Turquety, D. Hurtmans, J. Hadji-Lazaro, and C. Clerbaux, 2005: Retrieval and characterization of ozone vertical profiles from a thermal infrared nadir sounder. J. Geophys. Res., 110, D24303, https://doi.org/10.1029/2005JD005845.

Comer, R. E., A. Slingo, and R. P. Allan, 2007: Observations of the diurnal cycle of outgoing longwave radiation from the Geostationary Earth Radiation Budget instrument. Geophys. Res. Lett., 34, L02823, https:// doi.org/10.1029/2006GL028229.

Crevoisier, C., and Coauthors, 2014: Towards IASI-New Generation (IASI-NG): Impact of improved spectral resolution and radiometric noise on the retrieval of thermodynamic, chemistry and climate variables. Atmos. Meas. Tech., 7, 4367-4385, https:// doi.org/10.5194/amt-7-4367-2014.
Doniki, S., D. Hurtmans, L. Clarisse, C. Clerbaux, H. M. Worden, K. W. Bowman, and P.-F. Coheur, 2015: Instantaneous longwave radiative impact of ozone: An application on IASI/ MetOp observations. Atmos. Chem. Phys., 15, 12 971-12 987, https://doi.org/10.5194/acp-15-12971-2015.

Duvel, J.-P., and Coauthors, 2001: The ScaRaB-Resurs Earth radiation budget dataset and first results. Bull. Amer. Meteor. Soc., 82, 1397-1408, https://doi.org/10.1175/1520-0477(2001) 082<1397:TSRERB > 2.3.CO;2.

Ellingson, R. G., D. J. Yanuk, H.-T. Lee, and A. Gruber, 1989: A technique for estimating outgoing longwave radiation from HIRS radiance observations. J. Atmos. Oceanic Technol., 6, 706-711, https:// doi.org/10.1175/1520-0426(1989)006<0706:ATFEOL>2.0.CO;2.

Fasullo, J. T., and K. E. Trenberth, 2008: The annual cycle of the energy budget. Part II: Meridional structures and poleward transports. J. Climate, 21, 2313-2325, https://doi.org/10.1175/ 2007JCLI1936.1.

Feldman, D. R., C. A. Algieri, J. R. Ong, and W. D. Collins, 2011: CLARREO shortwave observing system simulation experiments of the twenty-first century: Simulator design and implementation. J. Geophys. Res., 116, D10107, https://doi.org/ 10.1029/2010JD015350.

Gristey, J. J., J. C. Chiu, R. J. Gurney, C. J. Morcrette, P. G. Hill, J. E. Russell, and H. E. Brindley, 2018: Insights into the diurnal cycle of global Earth outgoing radiation using a numerical weather prediction model. Atmos. Chem. Phys., 18, 5129-5145, https://doi.org/10.5194/acp-18-5129-2018.

Guidard, V., N. Fourrié, P. Brousseau, and F. Rabier, 2011: Impact of IASI assimilation at global and convective scales and challenges for the assimilation of cloudy scenes. Quart. J. Roy. Meteor. Soc., 137, 1975-1987, https://doi.org/10.1002/qj.928.

Han, Y., and Coauthors, 2013: Suomi NPP CrIS measurements, sensor data record algorithm, calibration and validation activities, and record data quality. J. Geophys. Res. Atmos., 118 12 734-12 748, https://doi.org/10.1002/2013JD020344.

Harries, J., and Coauthors, 2008: The far-infrared Earth. Rev. Geophys., 46, RG4004, https://doi.org/10.1029/2007RG000233.

Hilton, F., and Coauthors, 2012: Hyperspectral Earth observation from IASI: Five years of accomplishments. Bull. Amer. Meteor. Soc., 93, 347-370, https://doi.org/10.1175/BAMS-D11-00027.1.

Huang, X., V. Ramaswamy, and M. D. Schwarzkopf, 2006: Quantification of the source of errors in AM2 simulated tropical clear-sky outgoing longwave radiation. J. Geophys. Res., 111, D14107, https://doi.org/10.1029/2005JD006576.

_- W. Yang, N. G. Loeb, and V. Ramaswamy, 2008: Spectrally resolved fluxes derived from collocated AIRS and CERES measurements and their application in model evaluation: Clear sky over the tropical oceans. J. Geophys. Res., 113, D09110, https://doi.org/10.1029/2007JD009219.

_, N. G. Loeb, and W. Yang, 2010: Spectrally resolved fluxes derived from collocated AIRS and CERES measurements and their application in model evaluation: 2. Cloudy sky and band-by-band cloud radiative forcing over the tropical oceans. J. Geophys. Res., 115, D21101, https://doi.org/ 10.1029/2010JD013932.

— , X. Chen, G. L. Potter, L. Oreopoulos, J. N. S. Cole, D. Lee, and N. G. Loeb, 2014: A global climatology of outgoing longwave spectral cloud radiative effect and associated effective cloud properties. J. Climate, 27, 7475-7492, https:// doi.org/10.1175/JCLI-D-13-00663.1.

Huang, Y., S. Leroy, P. J. Gero, J. Dykema, and J. Anderson, 2010: Separation of longwave climate feedbacks from spectral 
observations. J. Geophys. Res., 115, D07104, https://doi.org/ 10.1029/2009JD012766.

Inness, A., and Coauthors, 2019: The CAMS reanalysis of atmospheric composition. Atmos. Chem. Phys., 19, 3515-3556, https://doi.org/10.5194/acp-19-3515-2019.

Jacobowitz, H., W. L. Smith, H. B. Howell, F. W. Nagle, and J. R Hickey, 1979: The first 18 months of planetary radiation budget measurements from the Nimbus 6 ERB experiment J. Atmos. Sci., 36, 501-507, https://doi.org/10.1175/15200469(1979)036<0501:TFMOPR > 2.0.CO;2.

- - , H. V. Soule, H. L. Kyle, and F. B. House, 1984: The Earth Radiation Budget (ERB) experiment: An overview. J. Geophys. Res., 89, 5021-5038, https://doi.org/ 10.1029/JD089iD04p05021.

Jones, C., L. M. V. Carvalho, R. W. Higgins, D. E. Waliser, and J.-K. E. Schemm, 2004: Climatology of tropical intraseasonal convective anomalies: 1979-2002. J. Climate, 17, 523539, https://doi.org/10.1175/1520-0442(2004)017<0523:COTICA > 2.0.CO;2.

Kandel, R., and Coauthors, 1998: The ScaRaB Earth radiation budget dataset. Bull. Amer. Meteor. Soc., 79, 765-783, https:// doi.org/10.1175/1520-0477(1998)079<0765:TSERBD>2.0. $\mathrm{CO} ; 2$.

Kidson, J. W., M. J. Revell, B. Bhaskaran, A. B. Mullan, and J. A. Renwick, 2002: Convection patterns in the tropical Pacific and their influence on the atmospheric circulation at higher latitudes. J. Climate, 15, 137-159, https://doi.org/10.1175/15200442(2002)015<0137:CPITTP>2.0.CO;2.

Kiladis, G. N., K. H. Straub, and P. T. Haertel, 2005: Zonal and vertical structure of the Madden-Julian oscillation. J. Atmos. Sci., 62, 2790-2809, https://doi.org/10.1175/JAS3520.1.

Lau, K.-M., and P. H. Chan, 1983a: Short-term climate variability and atmospheric teleconnections from satellite-observed outgoing longwave radiation. Part I: Simultaneous relationships. J. Atmos. Sci., 40, 2735-2750, https://doi.org/10.1175/ 1520-0469(1983)040<2735:STCVAA > 2.0.CO;2.

$\ldots$, and 1983b: Short-term climate variability and atmospheric teleconnections from satellite-observed outgoing longwave radiation. Part II: Lagged correlations. J. Atmos. Sci., 40, 2751-2767, https://doi.org/10.1175/1520-0469(1983) $040<2751$ :STCVAA $>2.0$. CO 2 .

Lee, H.-T., and R. G. Ellingson, 2013: HIRS OLR climate data record-Production and validation updates. AIP Conf. Proc., 1531, 420, https://doi.org/10.1063/1.4804796.

Li, J., 2000: Gaussian quadrature and its application to infrared radiation. J. Atmos. Sci., 57, 753-765, https://doi.org/10.1175/ 1520-0469(2000)057<0753:GQAIAT >2.0.CO;2.

Loeb, N. G., N. M. Smith, S. Kato, W. F. Miller, S. K. Gupta, P. Minnis, and B. A. Wielicki, 2003: Angular distribution models for top-of-atmosphere radiative flux estimation from the Clouds and the Earth's Radiant Energy System instrument on the Tropical Rainfall Measuring Mission satellite. Part I: Methodology. J. Appl. Meteor., 42, 240-265, https://doi.org/ 10.1175/1520-0450(2003)042<0240:ADMFTO >2.0.CO;2.

_, S. Kato, K. Loukachine, and N. Manalo-Smith, 2005: Angular distribution models for top-of-atmosphere radiative flux estimation from the Clouds and the Earth's Radiant Energy System instrument on the Terra satellite. Part I: Methodology. J. Atmos. Oceanic Technol., 22, 338-351, https://doi.org/ 10.1175/JTECH1712.1.

_ - B. A. Wielicki, D. R. Doelling, G. L. Smith, D. F. Keyes, S. Kato, N. Manalo-Smith, and T. Wong, 2009: Toward optimal closure of the Earth's top-of-atmosphere radiation budget. J. Climate, 22, 748-766, https://doi.org/10.1175/ 2008JCLI2637.1.

, J. M. Lyman, G. C. Johnson, R. P. Allan, D. R. Doelling, T. Wong, B. J. Soden, and G. L. Stephens, 2012: Observed changes in top-of-the-atmosphere radiation and upper-ocean heating consistent within uncertainty. Nat. Geosci., 5, 110-113, https://doi.org/10.1038/ngeo1375.

, and Coauthors, 2018: Clouds and the Earth's Radiant Energy System (CERES) Energy Balanced and Filled (EBAF) topof-atmosphere (TOA) edition-4.0 data product. J. Climate, 31, 895-918, https://doi.org/10.1175/JCLI-D-17-0208.1.

Nalli, N., P. Minnett, and P. van Delst, 2008: Emissivity and reflection model for calculating unpolarized isotropic water surface-leaving radiance in the infrared. I: Theoretical development and calculations. Appl. Opt., 47, 3701-3721, https:// doi.org/10.1364/AO.47.003701.

Ohring, G., and A. Gruber, 1983: Satellite radiation observations and climate theory. Adv. Geophys., 25, 237-304, https:// doi.org/10.1016/S0065-2687(08)60175-2.

Prinn, R. G., and Coauthors, 2018: History of chemically and radiatively important atmospheric gases from the Advanced Global Atmospheric Gases Experiment (AGAGE). Earth Syst. Sci. Data, 10, 985-1018, https://doi.org/10.5194/essd-10-985-2018.

Sathiyamoorthy, V., B. P. Shukla, R. Sikhakolli, S. Chaurasia, B. Simon, B. S. Gohil, and P. K. Pal, 2013: Top of atmosphere flux from the Megha-Tropiques ScaRaB. Curr. Sci., 104, 16561661, https://www.jstor.org/stable/24092602.

Smith, G. L., and D. A. Rutan, 2003: The diurnal cycle of outgoing longwave radiation from Earth Radiation Budget Experiment measurements. J. Atmos. Sci., 60, 1529-1542, https://doi.org/ 10.1175/2997.1.

, R. N. Green, E. Raschke, L. M. Avis, J. T. Suttles, B. A. Wielicki, and R. Davies, 1986: Inversion methods for satellite studies of the Earth's radiation budget: Development of algorithms for the ERBE mission. Rev. Geophys., 24, 407-421, https://doi.org/10.1029/RG024i002p00407.

Snarey, M., N. K. Terrett, P. Willett, and D. J. Wilton, 1997: Comparison of algorithms for dissimilarity-based compound selection. J. Mol. Graphics Model., 15, 372-385, https:// doi.org/10.1016/S1093-3263(98)00008-4.

Soden, B. J., D. L. Jackson, V. Ramaswamy, M. D. Schwarzkopf, and $\mathrm{X}$. Huang, 2005: The radiative signature of upper tropospheric moistening. Science, 310, 841-844, https://doi.org/ 10.1126/science. 1115602 .

Stephens, G. L., and Coauthors, 2012: An update on Earth's energy balance in light of the latest global observations. Nat. Geosci., 5, 691-696, https://doi.org/10.1038/ngeo1580.

Su, W., J. Corbett, Z. Eitzen, and L. Liang, 2015: Next-generation angular distribution models for top-of-atmosphere radiative flux calculation from CERES instruments: Methodology. Atmos. Meas. Tech., 8, 611-632, https://doi.org/10.5194/amt-8611-2015.

Sun, F., M. D. Goldberg, X. Liu, and J. J. Bates, 2010: Estimation of outgoing longwave radiation from Atmospheric Infrared Sounder radiance measurements. J. Geophys. Res., 115, D09103, https://doi.org/10.1029/2009JD012799.

Suomi, V. E., 1960: The thermal radiation balance experiment on board explorer VII. JUNO ZZ Summary Project Rep., 247-278.

Susskind, J., C. D. Barnet, and J. M. Blaisdell, 2003: Retrieval of atmospheric and surface parameters from AIRS/ AMSU/HSB data in the presence of clouds. IEEE Trans. Geosci. Remote Sens., 41, 390-409, https://doi.org/10.1109/ TGRS.2002.808236. 
_ temperature sounding and quality control methodology using AIRS/AMSU data: The AIRS Science Team version 5 retrieval algorithm. IEEE Trans. Geosci. Remote Sens., 49, 883907, https://doi.org/10.1109/TGRS.2010.2070508.

, G. Molnar, L. Iredell, and N. G. Loeb, 2012: Interannual variability of outgoing longwave radiation as observed by AIRS and CERES. J. Geophys. Res., 117, D23107, https:// doi.org/10.1029/2012JD017997.

_ J. M. Blaisdell, and L. Iredell, 2014: Improved methodology for surface and atmospheric soundings, error estimates, and quality control procedures: The Atmospheric Infrared Sounder science team version-6 retrieval algorithm. J. Appl. Remote Sens., 8, 084994, https://doi.org/10.1117/1.jrs.8.084994.

Suttles, J. T., and Coauthors, 1988: Angular radiation models for Earth-atmosphere system, Vol. I-Shortwave radiation. NASA Tech. Rep. NASA RP-1184, 144 pp.

- R. N. Green, G. L. Smith, B. A. Wielicki, I. J. Walker, V. R. Taylor, and L. L. Stowe, 1989: Angular radiation models for Earth-atmosphere system, Vol. II-Longwave radiation. NASA Tech. Rep. NASA RP-1184, 84 pp.

Taylor, V. R., and L. L. Stowe, 1984: Reflectance characteristics of uniform Earth and cloud surfaces derived from NIMBUS-7 ERB. J. Geophys. Res., 89, 4987-4996, https://doi.org/10.1029/ JD089iD04p04987.

Thomas, S., K. J. Priestley, P. C. Hess, R. S. Wilson, N. P. Smith, M. G. Timcoe, M. Shankar, and D. R. Walikainen, 2012: Performance of the Clouds and the Earth's Radiant Energy System (CERES) Flight Model 5 (FM5) instrument on NPP mission. Proc. SPIE, 8510, 851005, https://doi.org/10.1117/12.930775.

Trenberth, K. E., J. T. Fasullo, and J. Kiehl, 2009: Earth's global energy budget. Bull. Amer. Meteor. Soc., 90, 311-324, https:// doi.org/10.1175/2008BAMS2634.1.

_ — C C. O'Dell, and T. Wong, 2010: Relationships between tropical sea surface temperature and top-of-atmosphere radia- tion. Geophys. Res. Lett., 37, L03702, https://doi.org/10.1029/ 2009GL042314.

Turner, E., 2015: Evaluating spectral radiances simulated by the HadGEMS2 global climate model using longwave satellite measurements. Ph.D. thesis, University of Edinburgh, 200 pp., https://era.ed.ac.uk/bitstream/handle/1842/10047/ Turner2015.pdf.

- H.-T. Lee, and S. F. B. Tett, 2015: Using IASI to simulate the total spectrum of outgoing long-wave radiances. Atmos. Chem. Phys., 15, 6561-6575, https://doi.org/10.5194/acp-156561-2015.

Wielicki, B. A., B. R. Barkstrom, E. F. Harrison, R. B. Lee, G. L. Smith, and J. E. Cooper, 1996: Clouds and the Earth's Radiant Energy System (CERES): An Earth observing system experiment. Bull. Amer. Meteor. Soc., 77, 853-868, https://doi.org/10.1175/1520-0477(1996)077<0853:CATERE> 2.0.CO;2.

Wild, M., and Coauthors, 2014: The energy balance over land and oceans: An assessment based on direct observations and CMIP5 climate models. Climate Dyn., 44, 3393-3429, https:// doi.org/10.1007/s00382-014-2430-z.

Yang, Y., T. Li, K. Li, and W. Yu, 2015: What controls seasonal variations of the diurnal cycle of sea surface temperature in the eastern tropical Indian Ocean? J. Climate, 28, 8466-8485, https://doi.org/10.1175/JCLI-D-14-00826.1.

Zhang, K., M. D. Goldberg, F. Sun, L. Zhou, W. W. Wolf, C. Tan, N. R. Nalli, and Q. Liu, 2017: Estimation of near-real-time outgoing longwave radiation from Cross-Track Infrared Sounder (CrIS) radiance measurements. J. Atmos. Oceanic Technol., 34, 643-655, https://doi.org/10.1175/JTECH-D-15-0238.1.

Zhou, D., A. Larar, X. Liu, W. Smith, L. Strow, P. Yang, P. Schlüssel, and X. Calbet, 2011: Global land surface emissivity retrieved from satellite ultraspectral IR measurements. IEEE Trans. Geosci. Remote Sens., 49, 1277-1290, https:// doi.org/10.1109/TGRS.2010.2051036. 